\title{
إدارة الشباب لمورد الوقت \\ وعلاقته بمسمارسة أنشطة وقت الفراغ في السياحة الداخلية
}

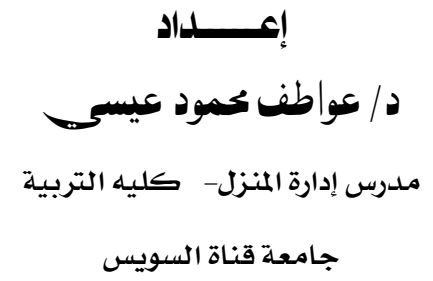

مجلة بحوث التزبية النوعية - جامعة المنصورة

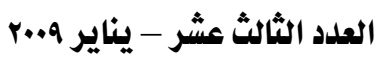




\section{وعلاقته بمهارسة أنشطة وقت الفراغ في السياحة الداخلية}

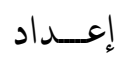

د /عواطف محمود عيسي

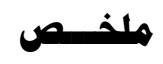

الوقت هو الحياة فعمـر الإنسان عبارة عن أيام وكما قال الحسن البصري"يا ابن آدم إنما أنت

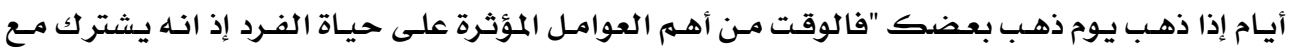

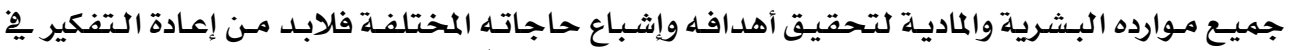

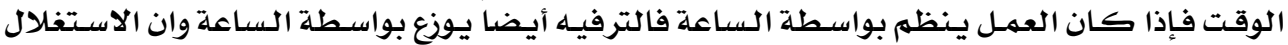

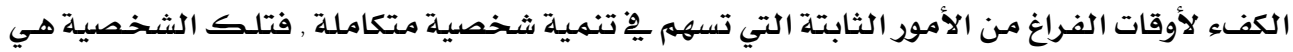

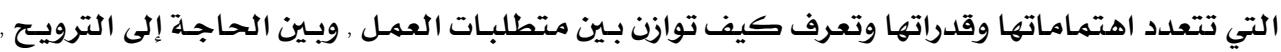

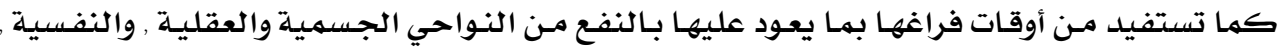
والتعبيرية الجمالية

لذلك لابد من إيجاد أنشطة مفيدة ومسليّة يِّ ذات الوقت . تسعاعد على تمكين الشباب

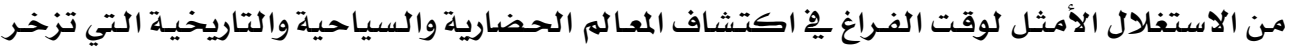

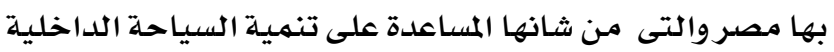
والدراسة الحالية تهدف إلى :

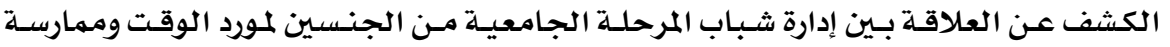

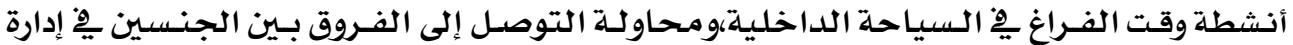

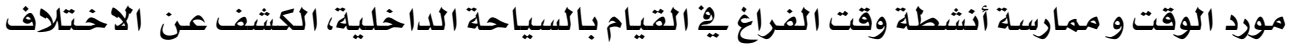

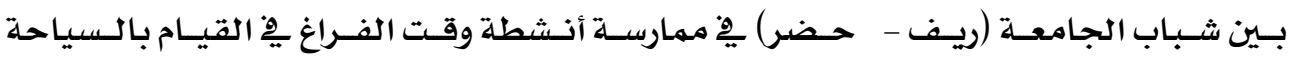
الداخلية

واشتملت أدوات الدراسلة على استبيـان إدارة مـورد الوقتو، اسـتبيان أنشطة وقت الفـراغ

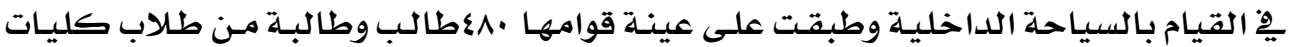

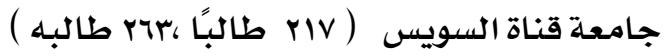
وكانت أهم النتائج ما يلب :

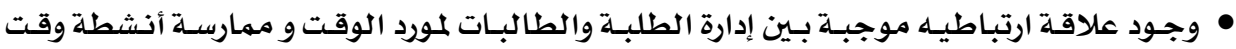

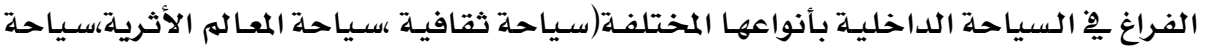

$$
\text { ترفيهية ،سياحة رياضية) }
$$




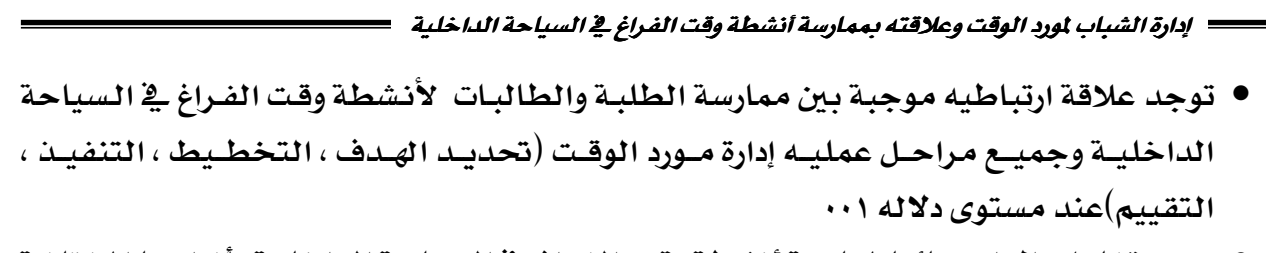

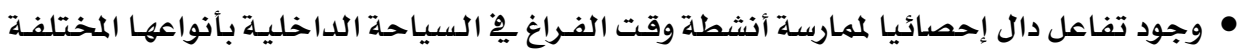

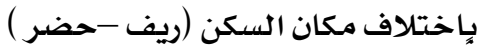

\title{
SUMMARY
}

\section{Youth resource management time and its relationship to the exercise of leisure-time activities in domestic tourism}

\author{
Dr. Awatef Mahmoud Eissa \\ Lecturer at the Department of Home Economics \\ Faculty of Education Ismailia \\ University of Suez Canal
}

\section{Introduction}

Time is the life of human life is a day-Hasan al-Basri said: "O son of Adam, but if you went on days gone

\section{Part of you}

"Time is of the most important factors affecting a person's life as he shares with all its human and material resources to achieve

its objectives and satisfy different needs must rethink If the time the work was regulated by the PM also Entertainment distributed by PM And the efficient exploitation of leisure is fixed, which contribute to the development of an integrated personality this is a vast personal interests, capabilities and know how to balance between work requirements and the need for recreation, and benefit from the leisure times of the beneficial aspects of physical and mental, psychological, And expressive and aesthetic Therefore, we should find a meaningful and fun at the same time. Helping to empower young people to make optimal use of leisure time to discover cultural landmarks and tourist and historical potential of Egypt, which would help the development of domestic tourism 


\section{The current study aims to;}

Disclosure of the relationship between the administration of the university youth of both sexes supplier time and the use of leisure time in domestic tourism, and try to find gender differences in the management of time and resource use of leisure time to do domestic tourism, disclosure of the difference between university students (Reeve attended) to exploit Leisure time to do domestic tourism

The tools included a questionnaire study resource management time the questionnaire and the use of leisure time to do domestic tourism has been applied to the sample (ns=480) of Suez Canal University (217 males\&263 females)

\section{The Research Results}

- There is a positive correlation between the administration of students and students of the time and resource use of leisure time in different kinds of domestic tourism (cultural, tourism, tourism monuments recreational tourism sports tourism)

- There is nothing positive correlation between the exploitation of students for leisure tourism in all stages of internal and supplier management process time (defining the goal planning, implementation Evaluation) at the level of significance 001 ,

- The interaction D Ahsaiyalastglal leisure tourism in the interior of different kinds, depending on place of residence rural - present).(

- There is no statistically Tvaa D resource management time Almokhtlav different aspects of residence(rural presen) 


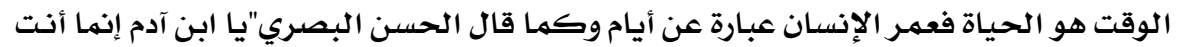

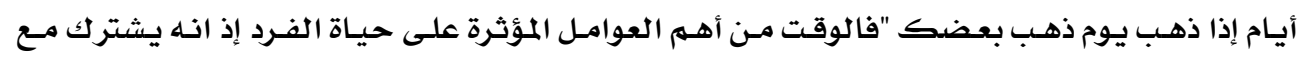

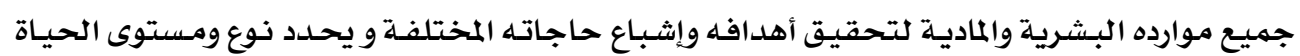

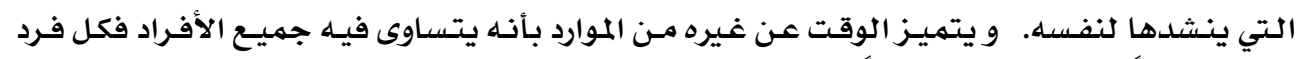

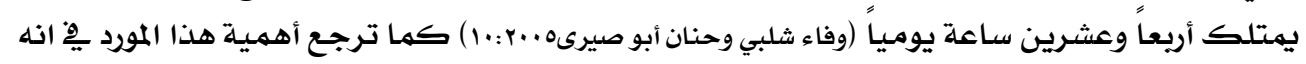

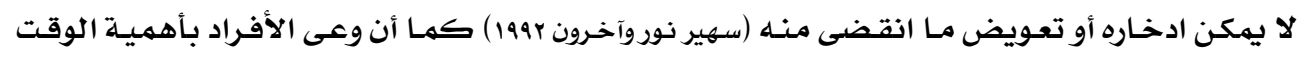

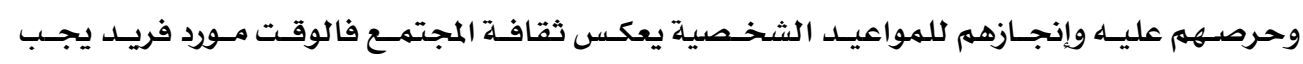

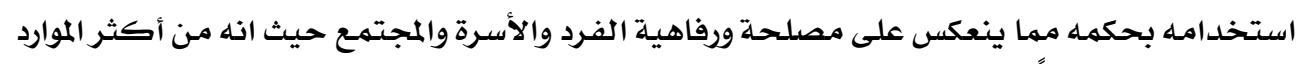

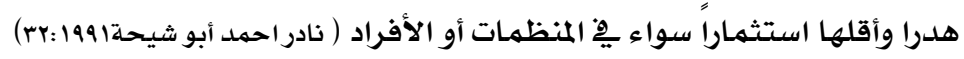
فكل فرد لديه نفس عدد الساعات ولكن كمية الوقت ليست مهمـة بقدر كيفيـة إدارة المتاح

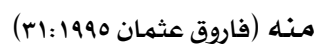

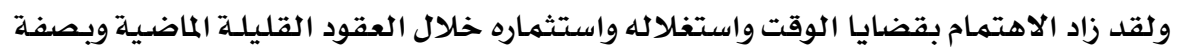

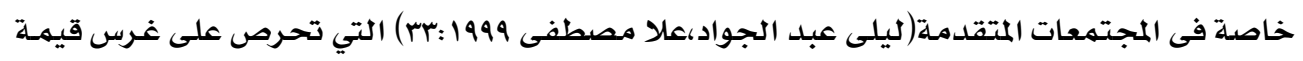

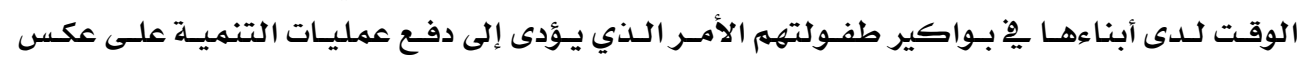

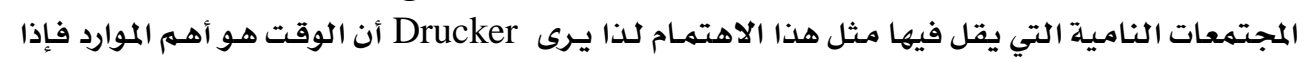

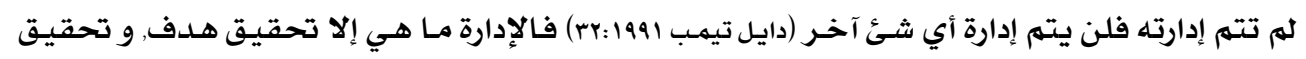

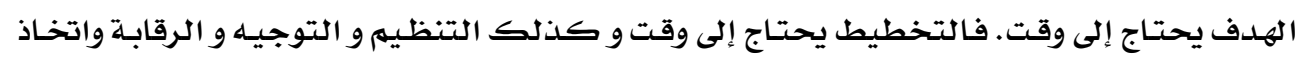

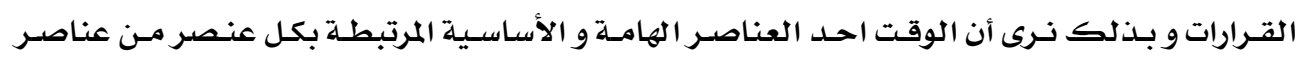

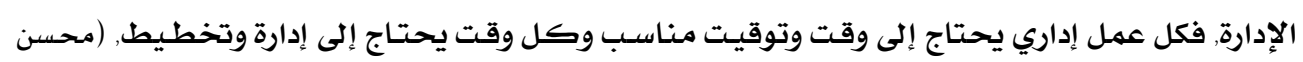

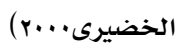

وتختلف إدارة مورد الوقت عن إدارة الموارد الأخرى فإدارة الوقت تعنى إدارة الـات فالشخص

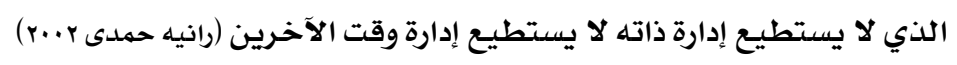

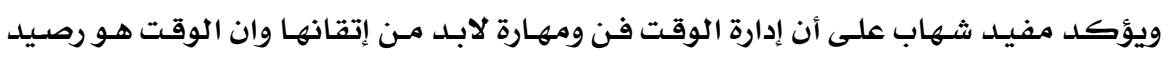

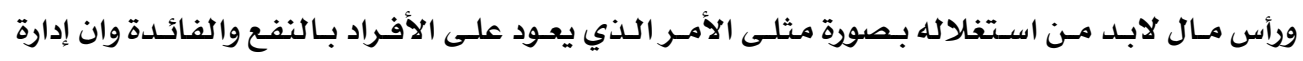

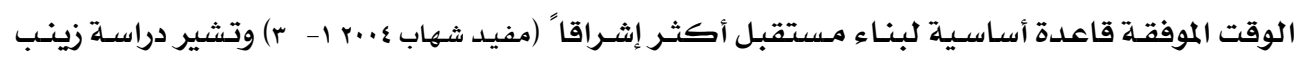

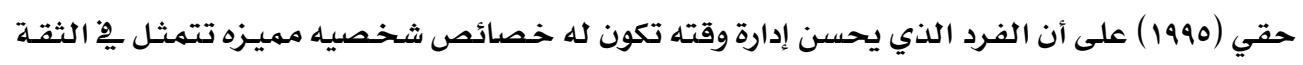

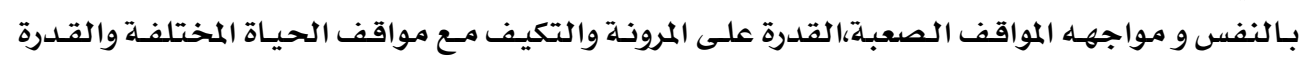

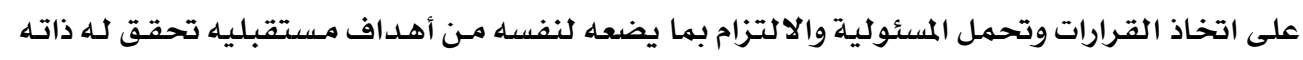

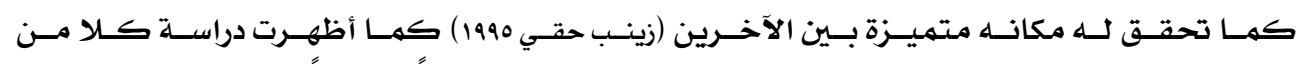

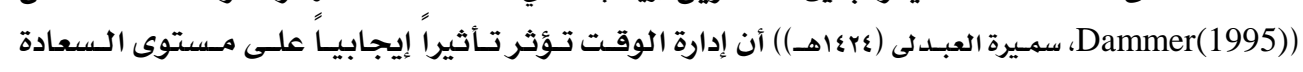

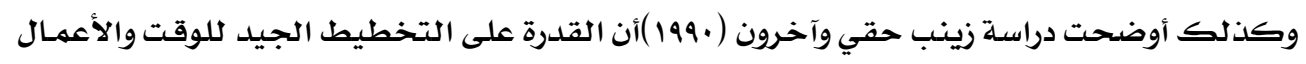




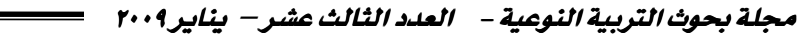

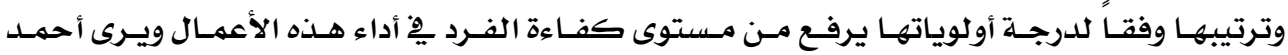

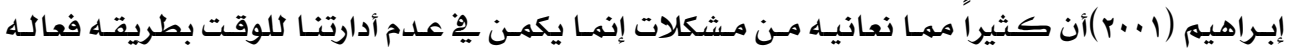
وذلك لان الإحسـاس بقيمة الوقت ما زال ضعيفا

وتـــكر " سـهير نـور"أن سـاعات اليـوم مقسسمـة إلى وقـت للعمـل Work ووقـت للنـوم والراحسة

ووقت للفراغ Leisure Time بحيث يستطيـ الفـرد القيـام بهسئوليـاته المختلفـة مـع التمتع بوقت للراحسة ووقت فراغ يهـارس فيـه هواياتـه وأنشطته الخاصسة.ويختلـف توزيـع سـاعات اليوم على تلك الأنشطة بـاختلاف الفرد .وتؤكد دراسـة كلا مـن( ذيلى عبـد الجـواد وعلا مـصطفى 1999 ) بأن تخصيص الوقت لأنشطة الحياة اليوميـة يتم توزيعها كما يلي: أ أنشطة ضـروريـة لاسـتمـرار حيـاة الفـرد والأسـرة وقـد أطلق عليهـا الوقت الملـزم ( committed

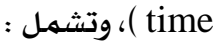

\section{أ- العمل يخ الوظيفة الأساسية}

\section{ب- الالتزامات الأسـرية بها تتضهنـه من أعمال ومسئوليات منزلية}

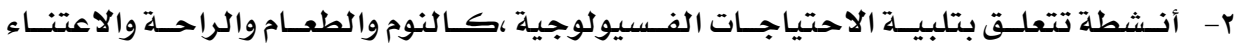
بالمظهر وخلافة

ب- الوقت المتبقي بعد ذلك وهو ما يطلق عليه الوقت الحر أو وقت الفراغ (leisure time) ويعتبر وقت الفـراغ سـلوكا اجتمهاعيـا يههـد لحركـة العمـل والإبـداع، وذلـك يعـني أن وقت

الفراغ قد يأخذ طابعا سلبيا أو إيجابيا يِ مجال الحياة الاجتهاعية. ويتحلدد ذلك بطبيعة التوجها

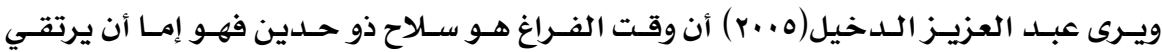
بشخصيـة الإنسـان وفكره وروحه ووجدانه وضميره وإما أن يكون بهثابـة عامـل مـدمر لشخصـية الإنسـان وصحته النفسية.

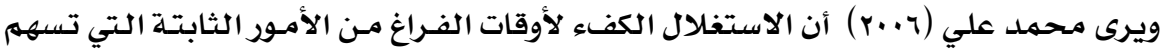

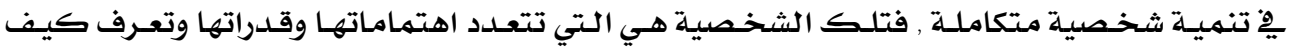
توازن بين مـتطلبـات العمل , وبيين الحـاجـة إلى الترويح , كما تستفيد من أوقات فراغها بهـا يعـود عليها بالنفـع من النواحي الجسميـة والعقليـة , والنفسية , والتعبيريـة والجماليـة فترى نانسي جمـال الدين (1999) أن مـن حق كل مواطن حرية استغلال أوقات فراغه يخ القيام بحركة سياحية داخل بلده الأمـر الدذي يؤدى إلى تعميـق انتهـاء المواطن لبلـده وتعميـق وعيـه بهويتـه وحرهـه على المحافظلة على تراث بلده فالسياحلة الداخلية تعتبر نشاط ذو أهميـة كبيرة سـواء للدول المتقدمـة أو الدول النـاميـة ويـرى كـلا مـن (Weaner and Oppermann2000) \& BTR1997) أن السياحة ظـاهرة إنسانية قديهـة وقد

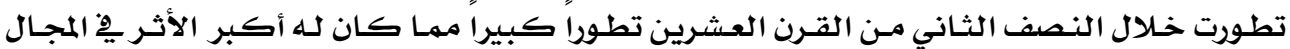
الاقتصادي والاجتماعي والثقايِّوالسياسي والبيئسي لذا تزايد الاهتمام العالمي بها بوصفها مـن أكبر

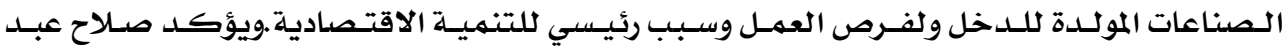
الوهاب( ع991 ) على أهميـة السياحة الداخلية بقوله أنها الركيزة الأسـاسية التي يعتمد عليها النشاط 
السياحي ككل، الأمر الذي أدى إلى الاهتمام الكبير بالسياحة الداخلية يْ مصر والعمل على تنميتها

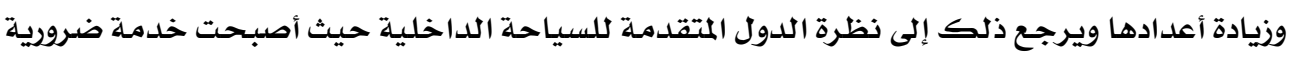

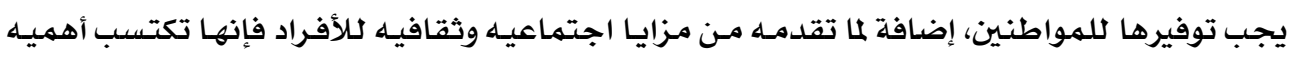

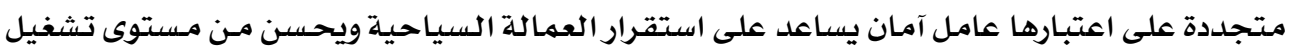

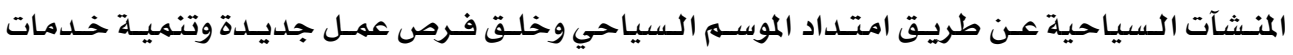

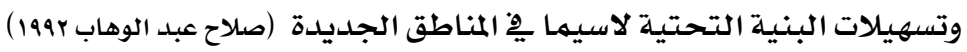

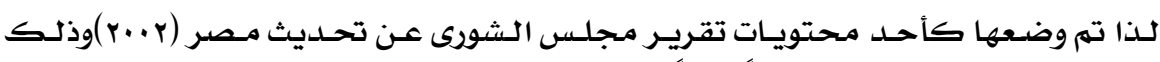

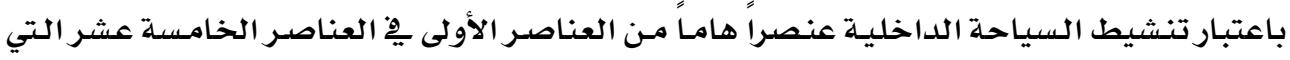

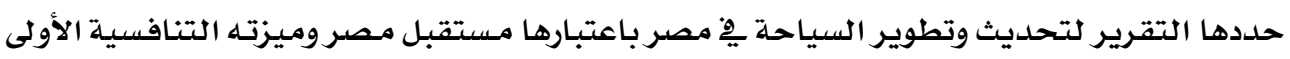

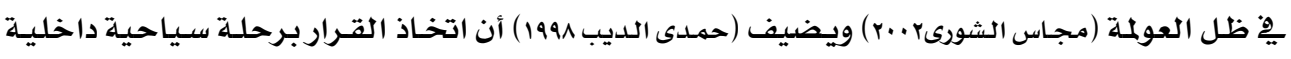

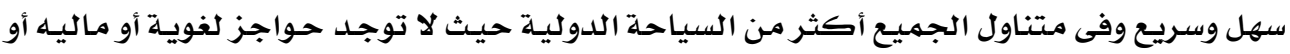

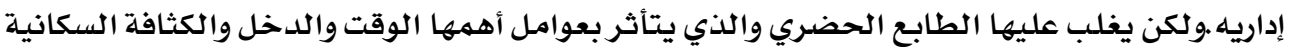

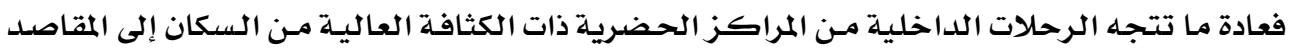

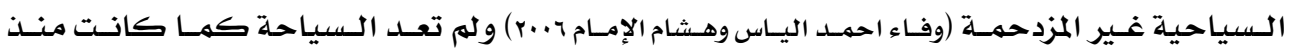

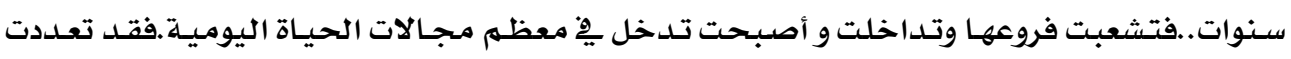

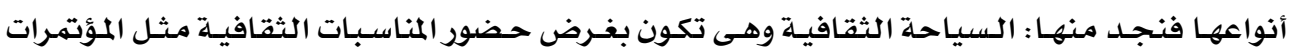

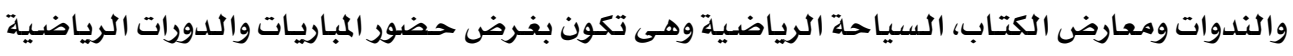

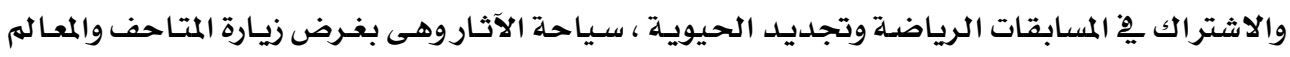

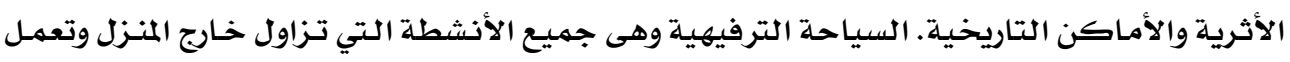

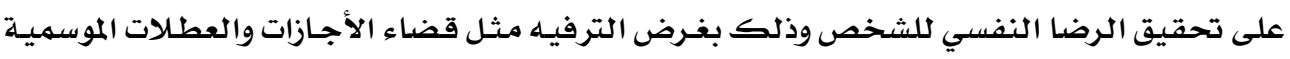

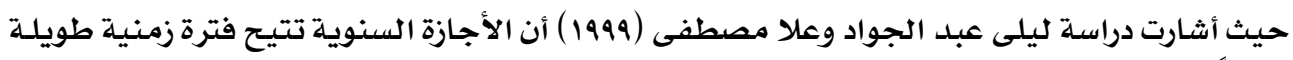

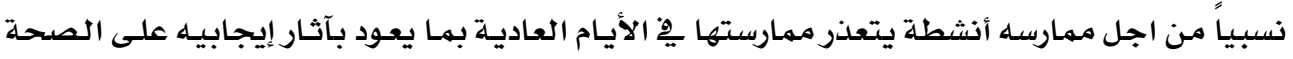

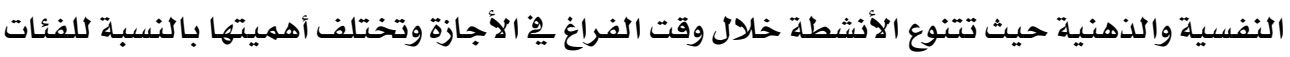

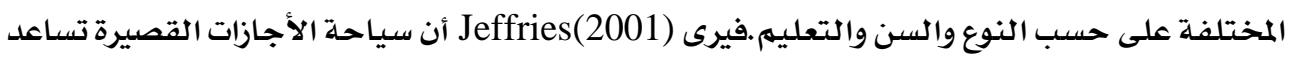
بصورة كبيرة على تنشيط العديد من أنواع السياحسة الداخليـة مثل السياحة الترفيهيـة والاستجمهام

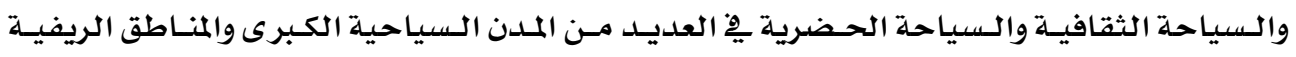
والثقافية والساحلية .

$$
\text { وتنقسم السياحة وفقا للفئة العمرية إلى : }
$$

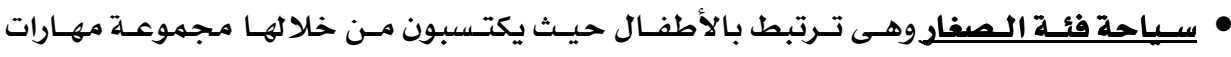

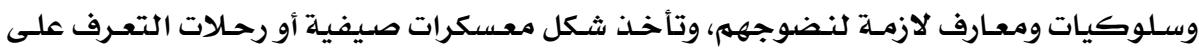

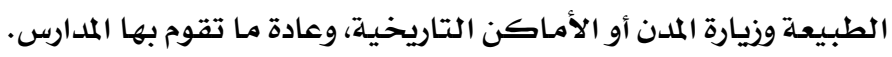




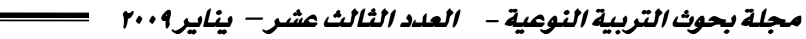

• سيـاحة فئة الشبـاب، وتهتاز هذه النوعيـة مـن السياحة بـالبحـث عن الإثارة والحيـاة لاجتمهاعيـة

المتجددة وتكوين الصداقات، وعادة تقوم بها الجـامعات من خلال الشركات لسياحية.

• سياحة فئة النـاضحيني، وتتهيز بكونها سياحة الاسترخاء من عناء العهل والإرهاق طوال العـام،

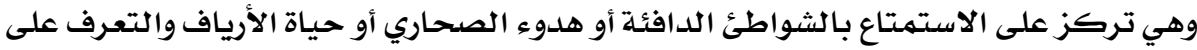

التقاليد القديهة.

وحيث إن مـرحلة الشبـاب تتحـدد فيها هويـة الفـرد وقيهـة واتجاهاتـه يِّ الحيـاة والعهـل فهي

المرحلة التي يكتمل فيها نموه العقلي والانفعالي ومن ثم يكون قـادر على تحمـل المسئولية والاستقلالال الاقتصادي (نبيل الزهار 1990) ـ فعلى قدر ما لدى الشبـاب من وعى بقيمـة الوقت وأهميـة تنظيمسه وإدارتـه إدارة حكيمـة تتوقف درجـة نجاحه يِ استثمار طاقاته و إمكانياته (زينب حقى 1990) وأوضحت ذلك دراسـة Britton\&Tesser(1991)

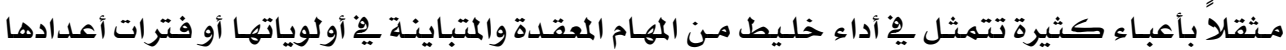

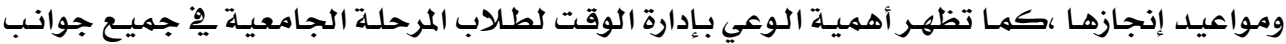
حياتهم الاجتهاعية والاقتصـادية والتكنولوجيـة حتى يهكنهم إحـداث التكيف مـع البيئسة المحيطـة بهـم

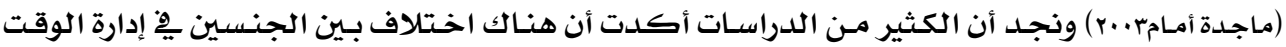
فأشـارت دراسـة كـل مـن (Macanet.a1990) \& (Mpofu, Damico, \& (Bee\&Raghy,1990) ( cleghorn1995) \& (Trueman \& Hartleg1996)

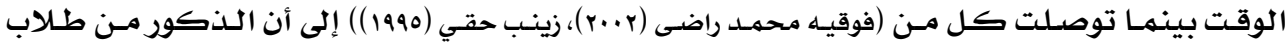

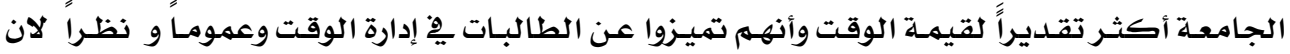

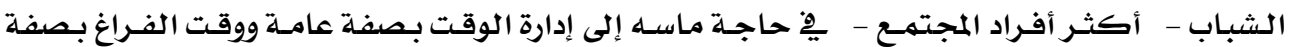

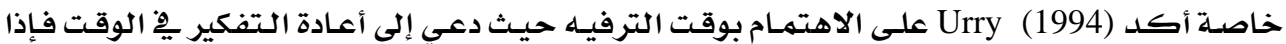
كان العمل ينظهم بواسطة السـاعة فالترفيـه أيضا يوزع بواسطة السـاعة لذلك لابد مـن إيجـاد أنشطة

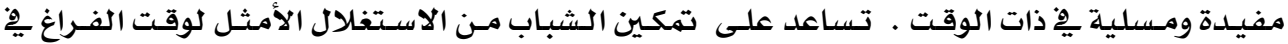

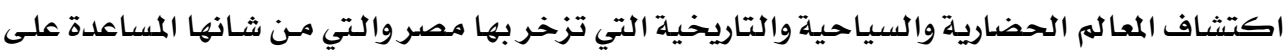
تنهية السياحة الداخلية

\section{مشكلة الدراسة}

يعد الاعتراف بأهميـة إدارة مورد الوقت بصفة عامـة ووقت الفـراغ بـففة خاصسة والعمل على

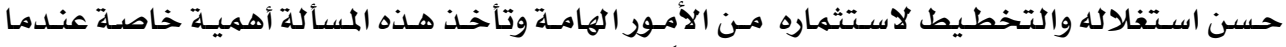

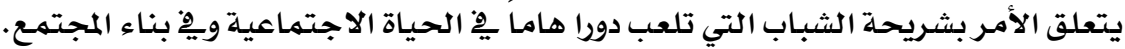
ففي الوقت الذي نجد فيـه المجتمعات المتقدمـة تولي أهميـة كبيرة لإدارة وقت الفـراغ نجـده فى مجتمعاتنا العربية مـا هو إلا وقت يجب القضاء عليه وإهداره

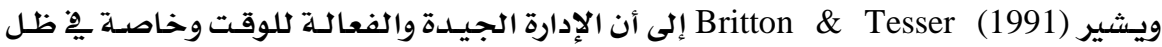
المتغيرات المعاصـرة يخ جميع جوانب الحيـاة تسـاعد على التكيف المطلـوب مـع هـذه المتغيرات الأمـر الذذي 


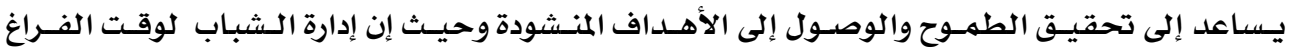

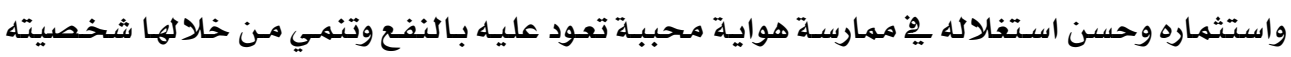

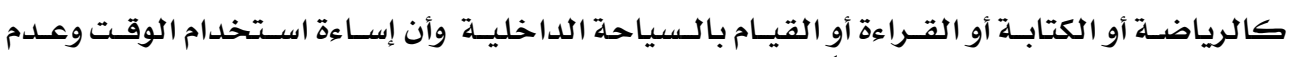

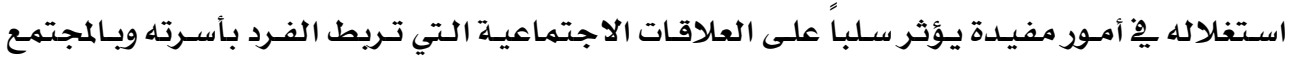

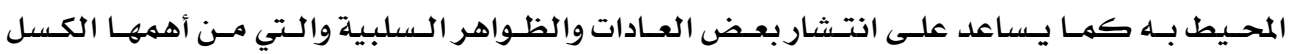

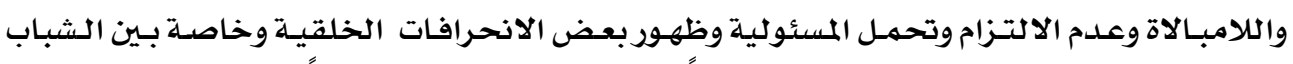

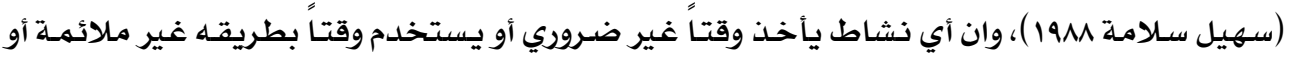

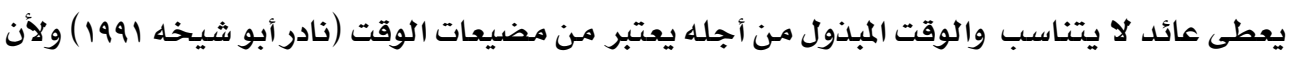

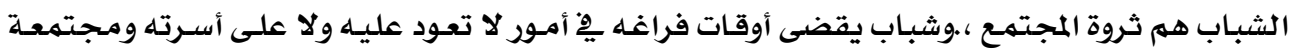

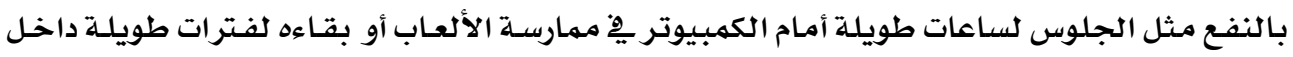
المنزل دون عمل.

فهو يعتبر بمثابة تحجيم فعلي لطاقة الشباب وإمكاناته الكامنة واستعداداته المختلفـة ولأن

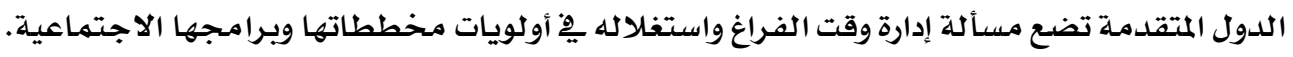

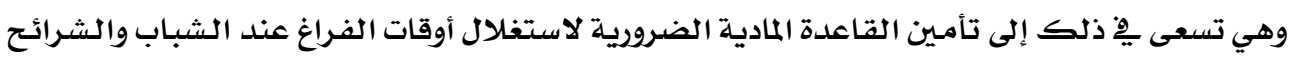

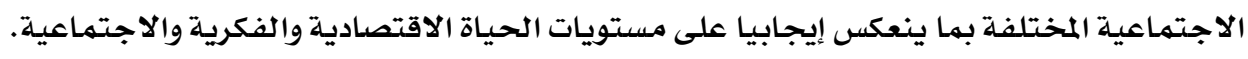

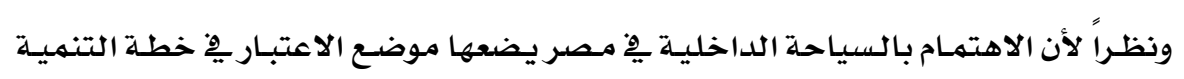

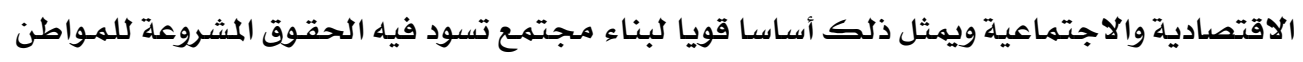

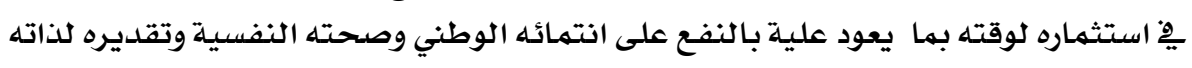

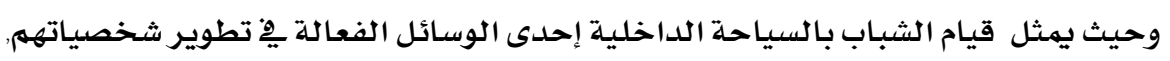

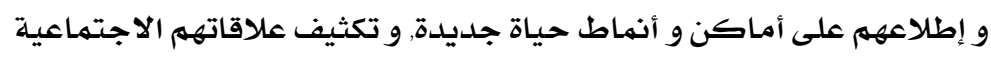

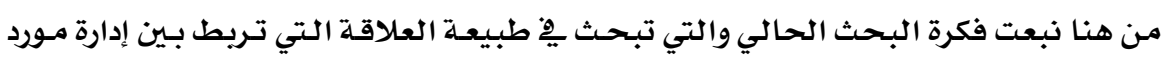

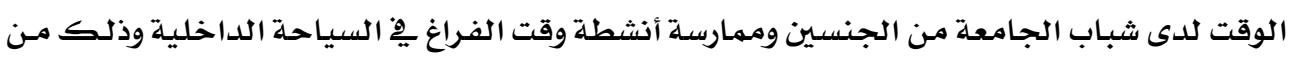

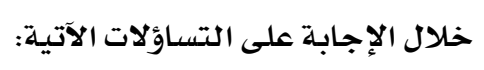

ا- ما هي طبيعة العلاقة بين محاور إدارة مورد الوقت لدى شباب الجامعلة من الجنسين و ممارسة

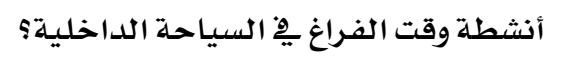

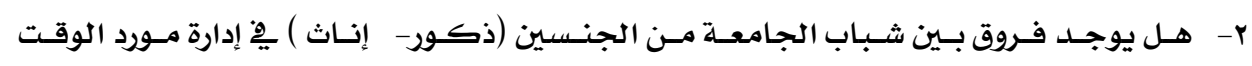

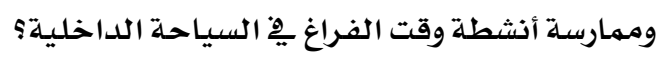

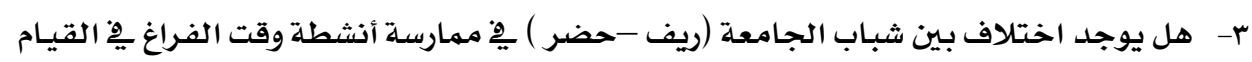

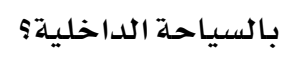

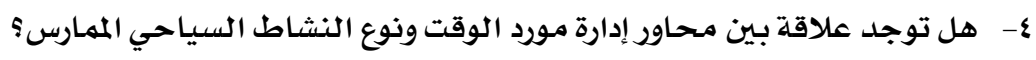

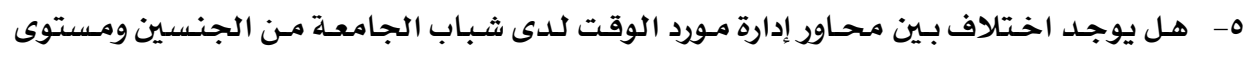

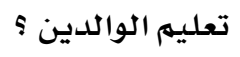




\section{أهداف الدراسة}

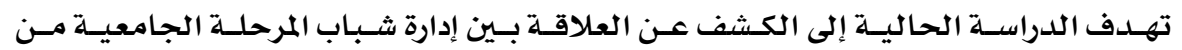

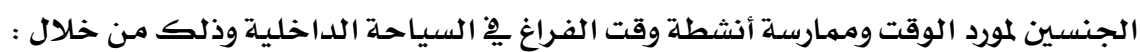

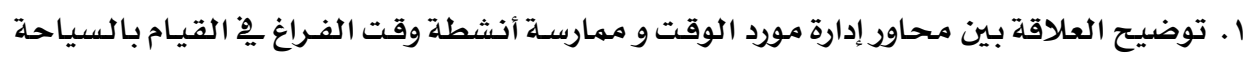

$$
\text { الداخلية }
$$

r. التعرف على الفروق بين الشباب من الجنسين ِِّ محاور إدارة مورد الوقت وممارسة أنشطة وقت

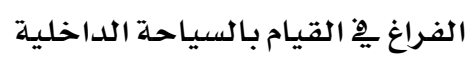

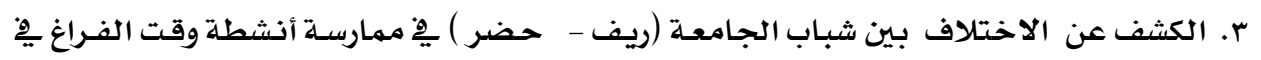

$$
\text { القيام بالسياحة الداخلية الاحتلاف بـن الافين }
$$

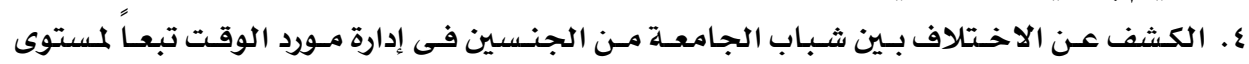

$$
\text { تعليه الوالدين }
$$

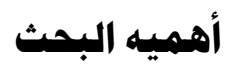

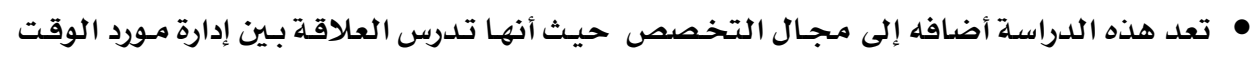

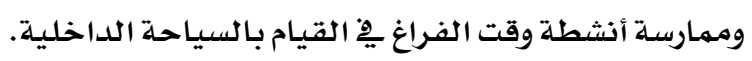

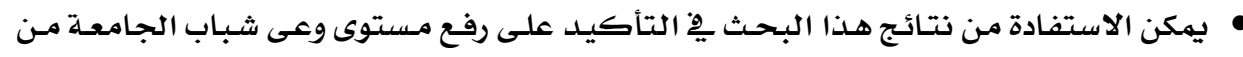

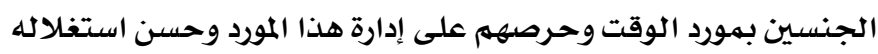

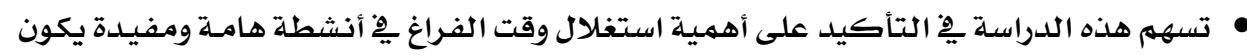

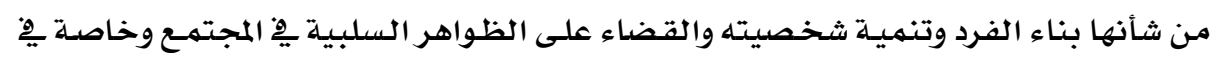
مرحلة الشباب حيث ذروة العطاء والإنتاج.

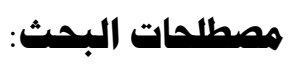

Management

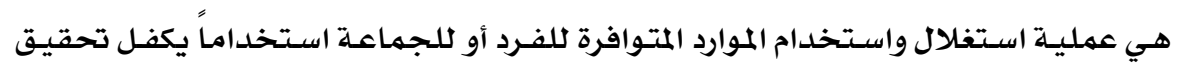

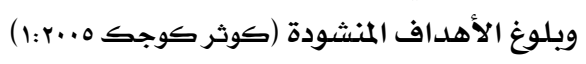

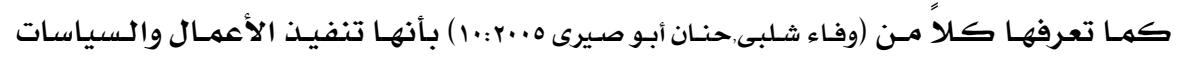

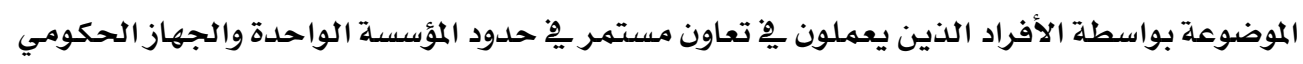

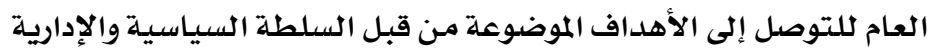

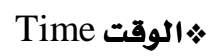

الوقت فِ اللغـة هـو كـل شـئ قدرت لـه حينـاً وكـذلك مـا قـدرت غايتـه فهـو مؤقت والوقت مقدار من الدهر معروف الوقت 


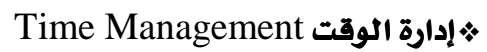
هي توجيـه القدرات الشخصية للأفراد وإعادة صـياغتها لانجـاز العهـل المطلوب وفقا للزمن والوقت المحدد يِّ ضوء القواعد والنظم المعمول بها (محمد عبد الغنى 1990)

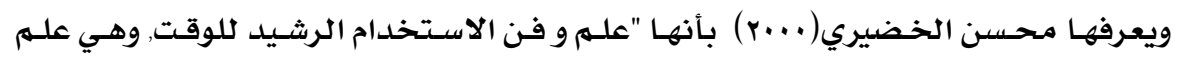

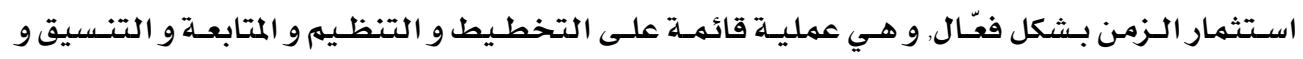

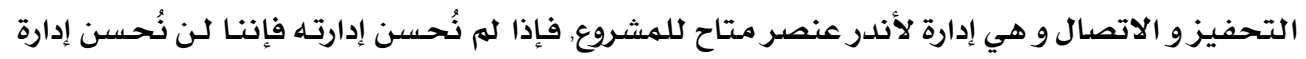
أي شيء.

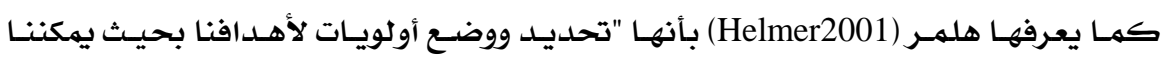
تخصيص وقت أكبر للمهام الهامـةووقت أقل للمهام البسيطة

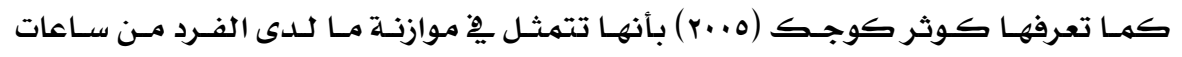

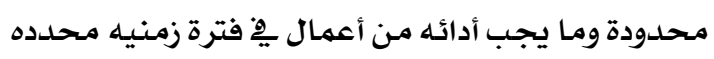

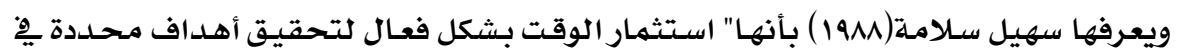
خلال فترة زمنية معينة

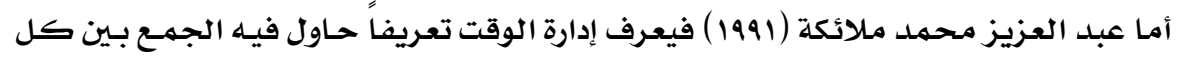

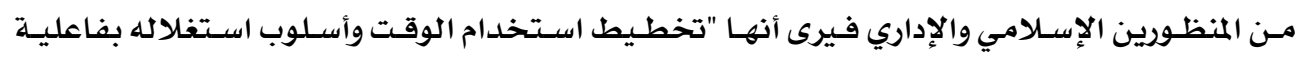

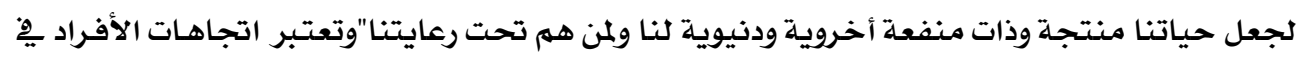

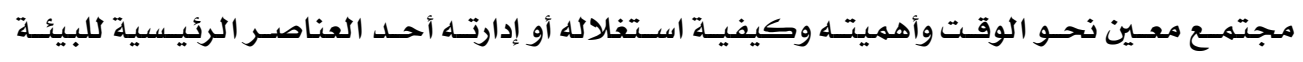

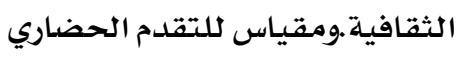

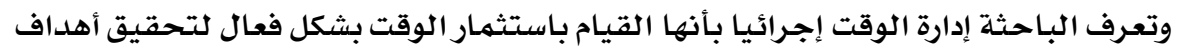

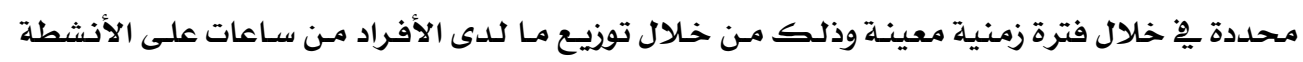
المختلفة حسب أهميتها

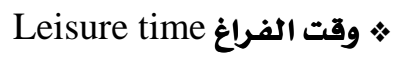

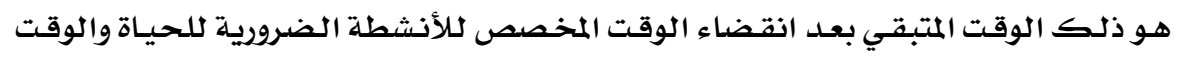

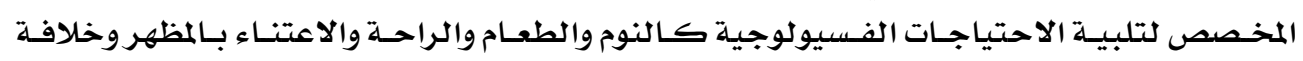

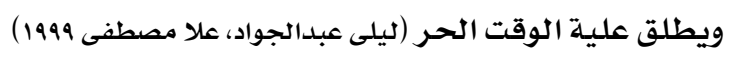
* السياحة وتعرف بأنها نشاط السفر بهدف الترفيه ، وتوفير الخدمات المتعلقة لهـذا النشاط. والسـائح

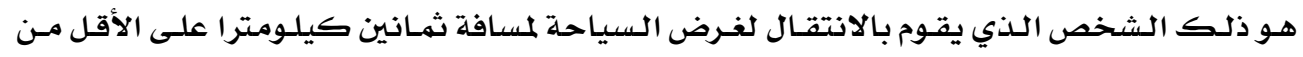
منزله. وذلك حسب تعريف منظمة السياحة العالمية (التابعة لهيئة الأممم المتحدة) 
Domestic Tourism السياحة الداخلية

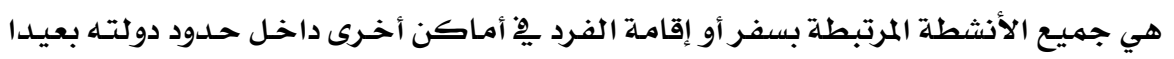

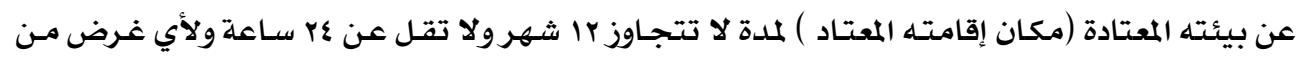

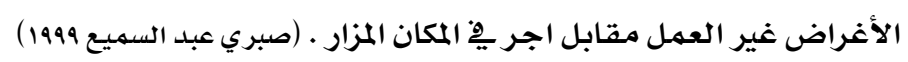

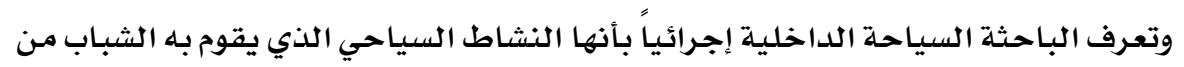

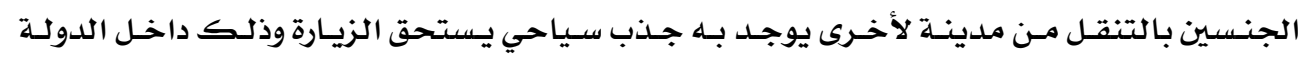
وتنقسهم إلى :

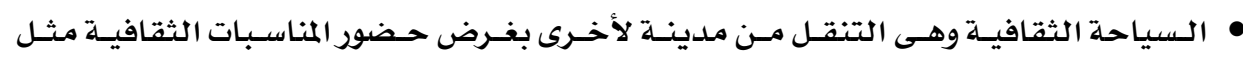

$$
\text { المؤتمرات والندوات ومعارض الثقافيـو الكتاب. }
$$

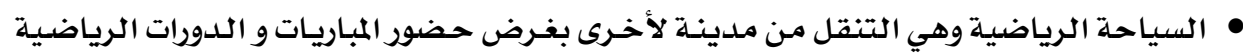

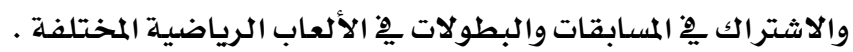

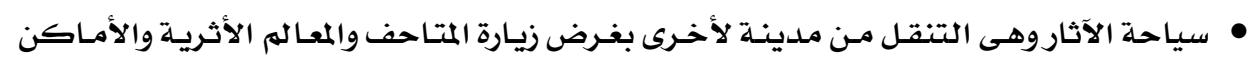

التاريخية.

• السياحة الترفيهيـة وهـى جميـع الأنشطة التي تـزاول خـارج المنـزل وتعهـل على تحقيـق الرضـا

$$
\text { النفسي للشخص وذلك بغرض الترفئ الترفيه. }
$$

فروض البمث النفي

ا- توجـد علاقـة ارتباطيـه بـين محساور إدارة مـورد الوقت وممارسسة أنشطة وقت الفـراغِيْ القيام

$$
\text { بالسياحة الداخلية }
$$

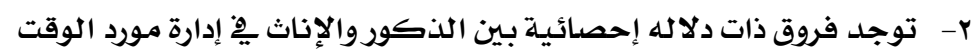

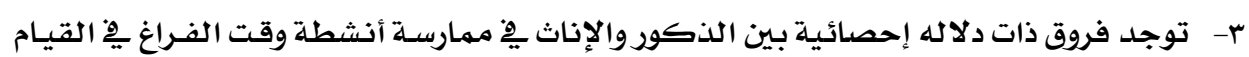

بالسياحة الداخلية

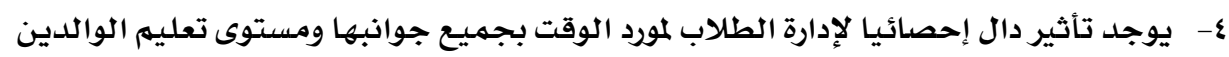

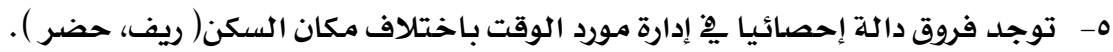

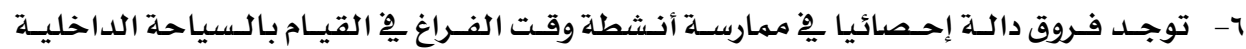

باختلاف مكان السكن( ريف، حضر دافيا ).

هنهمج البحث:

اتبع هذا البحث المنهج الوصفي التحليلي، ويقصد به وصف كل مـا هو كائن من خصائص

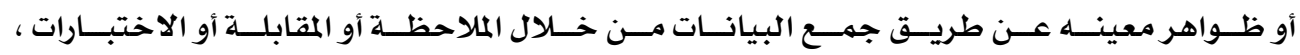

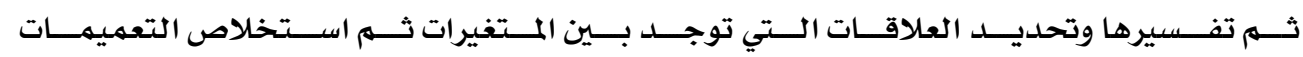


تتمثل حدود البحثث فيما يلي: أولاً:عينة البحث :

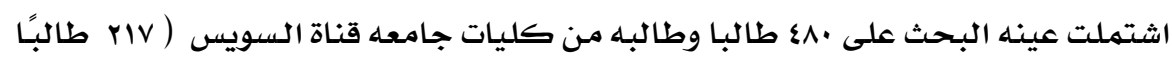

( الحدود الزمنية للبحث :

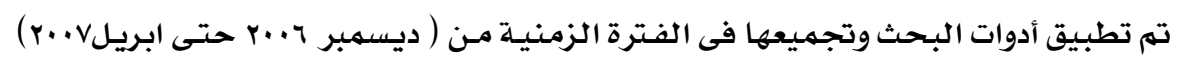

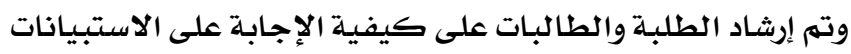
ثانياً: أدوات البحث:.

$$
\text { اشتملت أدوات البحث على : }
$$

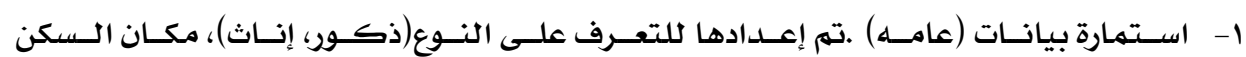

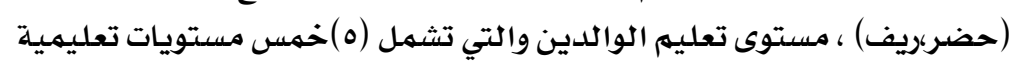

$$
\text { r- باستبيان إدارة الوقت. (إعداد الباحثة) . }
$$

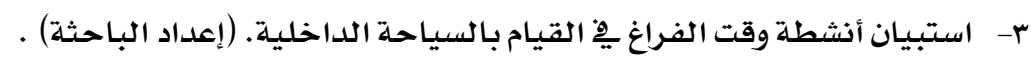

إعداد وبناء أدوات البحث

1. استمارة البيانات العامة:

وتم إعدادها للتعرف على (مكان سكن الأسرة (ريف- حضر)، مستوى تعليم الوالدين).

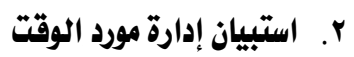

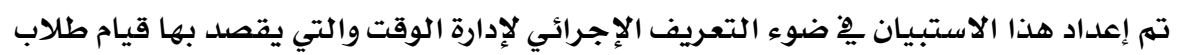

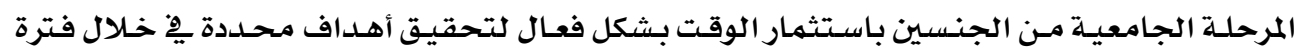

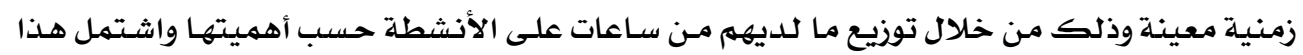

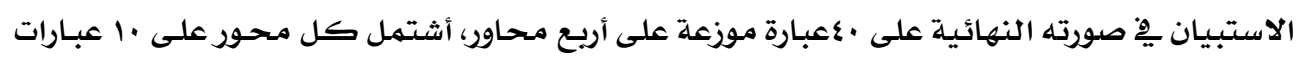

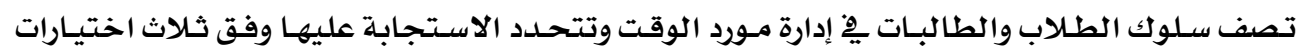

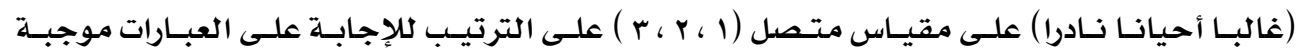

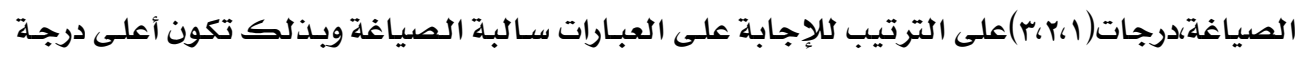

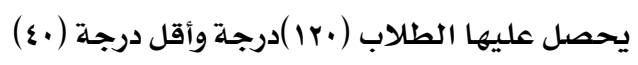

\section{• المحور الأول: تحديد الهدف علئابل}

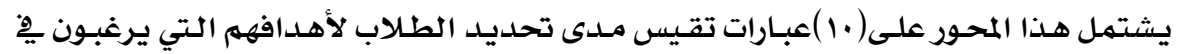

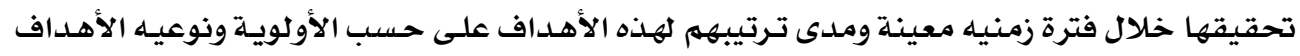
هل هي طويلة المدى أم قصيرة المدى فئري 
•

يتكـون هـذا المحـور مـن ( • )عبـارات تقـيس تخطيط الطـلاب لمورد الوقت وفقـا لوقـت العهـل

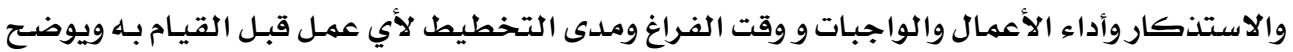

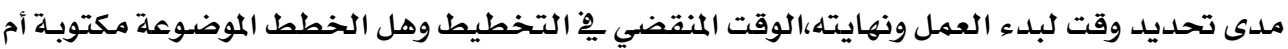

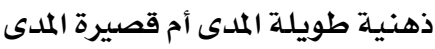
• المحور الثالث:التنفيذ

ويتضمن على ( • )عبارات تقيس التزام الطلاب بما وضعوه من خطط ومدىى الالتزام بالوقت

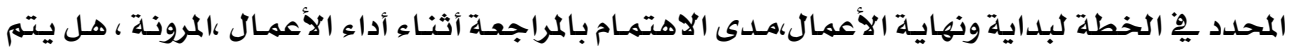

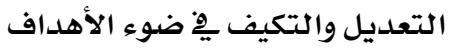
• المحور الرابع: التقييم ويشتمل على ( • )عبـارات تقـيس مـدى حـرص الطلبـة والطالبـات على تقيم الأداء والنتائج

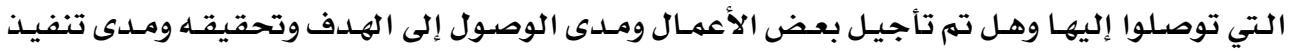

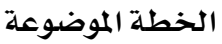
صدق الاستبيان:

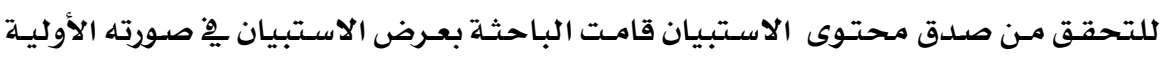

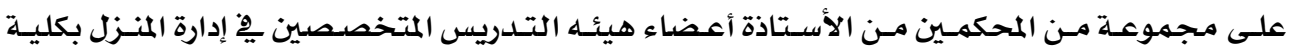

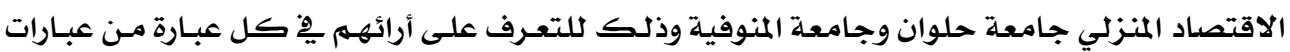

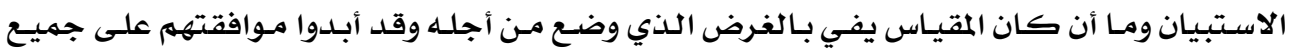

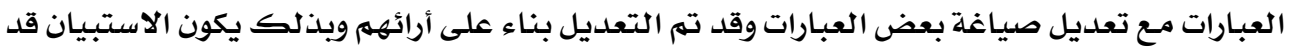

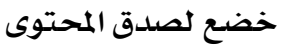
معامل الثبات :

تم تحديـد معامـل الثبـات باستخدام طريقـة ألفـا كرونبـاخ (Alpha Cronbach) وتراوحت

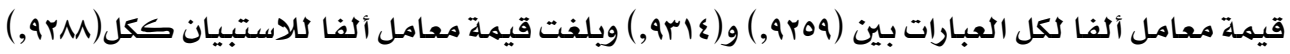

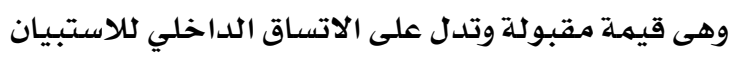

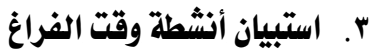

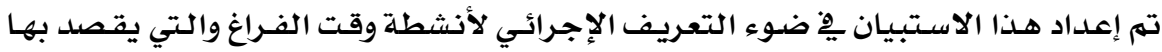

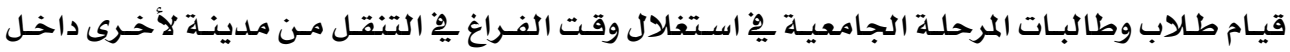

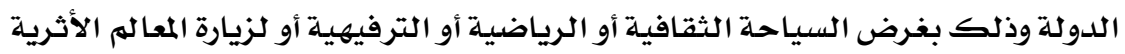

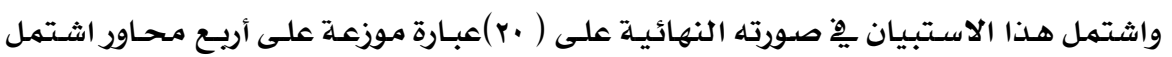

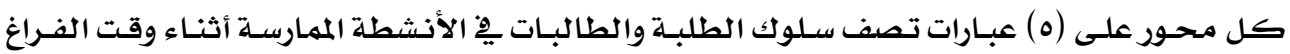

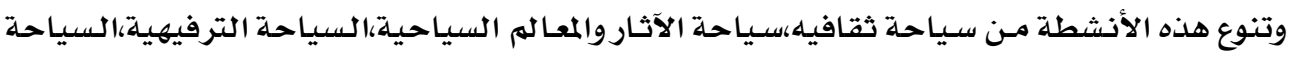




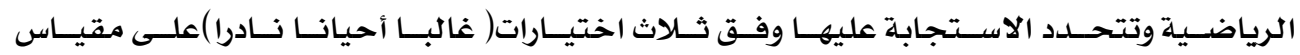

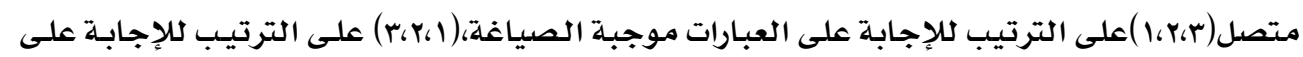

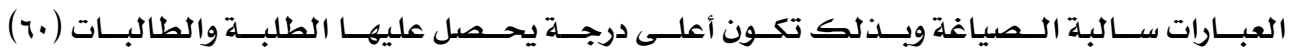

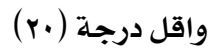

\section{• المحور الأول :السياحة الثقافية}

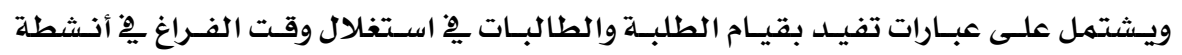

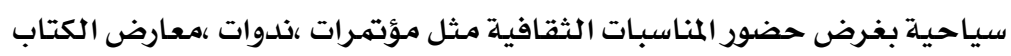
• المحور الثاني :

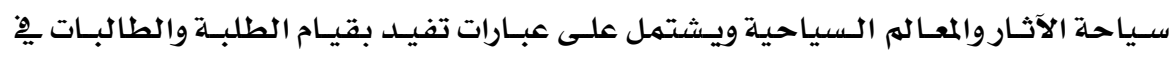

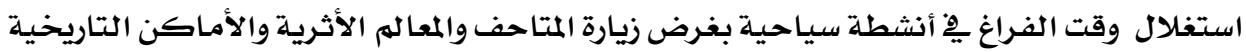
• المحور الثالث :السياحة الترفيهية

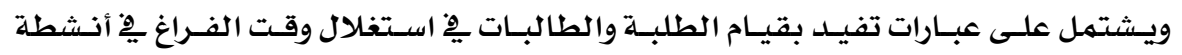

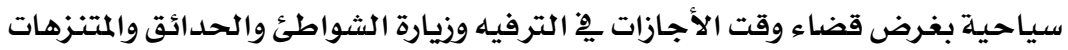

\section{• المحور الرابع:السياحة الرياضية برصية}

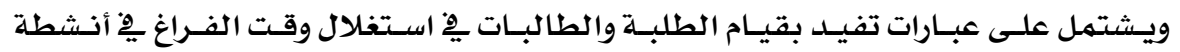

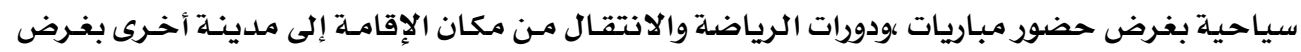

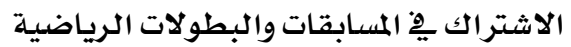

\section{صدق الاستبيـان:}

للتحقق مـن صـدق محتـوى الاسـتبيان قامست الباحثة بعـرض الاسـتبيان ِِّ صـورته الأوليـة

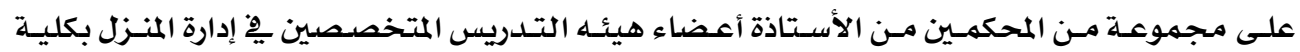

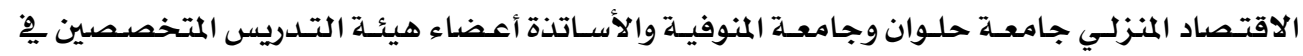

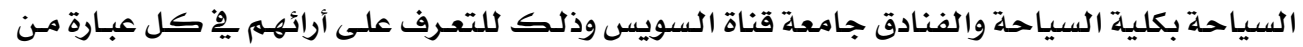

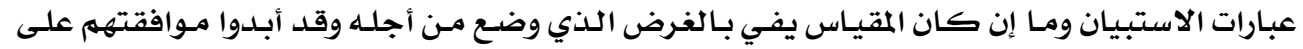

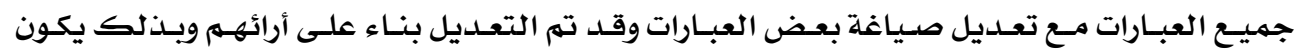

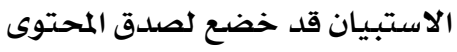
معامل الثبات

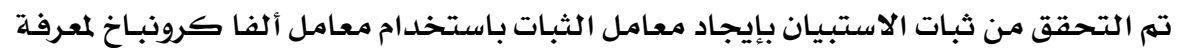

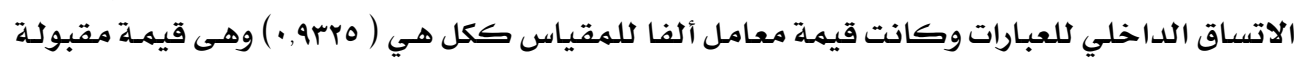
وتدل على الاتساق الداخلي للاستبيان 


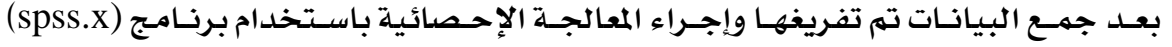

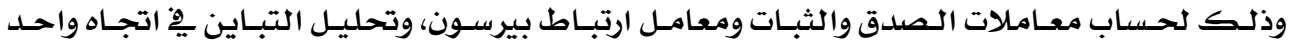

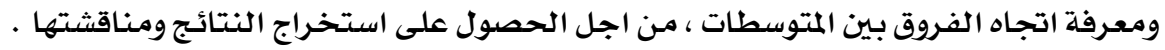

\section{نتائج الدراسة الميدانية وهناقشتها}

أولاً: توصيف العينة

\begin{tabular}{|c|c|c|}
\hline$\%$ & العلدد & الجنس \\
\hline$\%$ \%०, & YIN & ذكور \\
\hline$\%$ \% , 7 & rTY & إناث \\
\hline$\% 1 \ldots$ & $\varepsilon \wedge$. & مججموع \\
\hline
\end{tabular}

يتـضح مـن الجـــول السـابق أن نسبة الإنـاث كانـت أكثـر مـن نسبـة الـذكور حيـث بلغـت

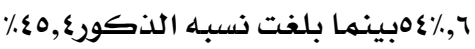
جدول (r ) توزيـع أفراد تبعا لمحل الإقامـة

\begin{tabular}{|c|c|c|}
\hline$\%$ & العدد & مكان السـكن \\
\hline$\% \mathrm{rV}$ & IVA & ريف \\
\hline \% & $r \cdot r$ & حضر \\
\hline$\% 1 \ldots$ & $\varepsilon \wedge$. & المجهوع \\
\hline
\end{tabular}

يتضـح من الجدول السـابق أن نسبـة أفراد العينـة مـن الحضر كانت أكثر مـن نسبـة الريـف

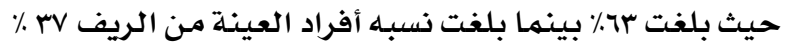
جدول ( r) توزيـع العينة تبعاً لمستوى تعليم الأم

\begin{tabular}{|c|c|c|}
\hline$\%$ & العدد & البيان \\
\hline- & - & يقرأ ويكتب \\
\hline$\%, 40$ & 19 & حاصلة على الابتدائية \\
\hline$\% 10, \varepsilon\}$ & VE & حاصلـة الثانويـة العامـة أو مـا يعادلها \\
\hline$\%$ \% TV & IVT & حاصل على شهادة فوق متوسطة بعد الثانويـة \\
\hline$\% \varepsilon r, 97$ & YII & حاصلة على شهادة جامعية ( بكالوريوس - ليسانس ) \\
\hline$\% 1 \cdots$ & $\varepsilon \wedge$. & المجهوع \\
\hline
\end{tabular}




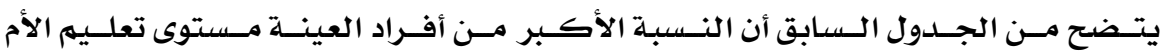

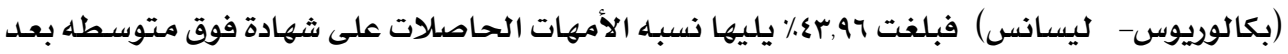

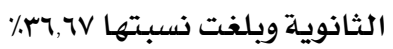

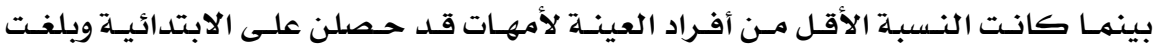

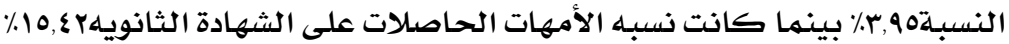

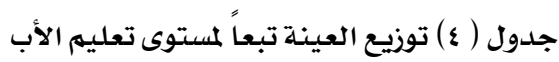

\begin{tabular}{|c|c|c|}
\hline$\%$ & 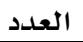 & 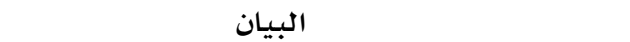 \\
\hline- & - & يقرأ ويكتب \\
\hline$\%, \mathrm{r \Lambda}$ & YI & حاصلة على الابتدائية \\
\hline$\% 10, \varepsilon Y$ & V乏 & حاصلـة الثانويـة العامـة أو مـا يعاد لها \\
\hline$\%$ \%^, ०६ & 110 & حاصل على شهادة فوق متوسطة بعد الثانويـة \\
\hline$\%$ \% , 77 & r.. & حاصلة على شهادة جامعية ( بكالوريوس - ليسانس ) \\
\hline$\% 1 \cdots$ & $\varepsilon \wedge$. & المجمهوع \\
\hline
\end{tabular}

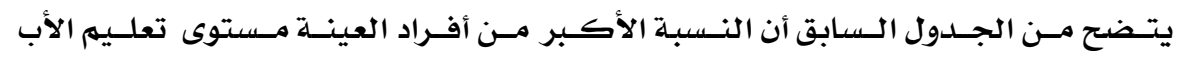

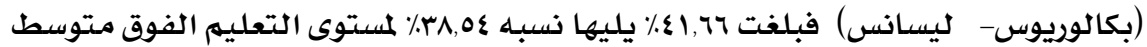

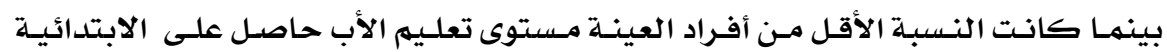

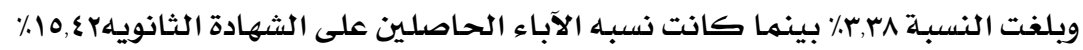

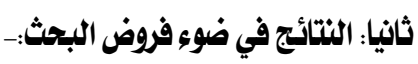
1- الفرض الأول: وينص على أنه :

توجد علاقة ارتباطيه بين محاور إدارة مورد الوقت وممارسة أنشطة وقت الفراغ فِّ القيام بالسياحة الداخلية توجلة

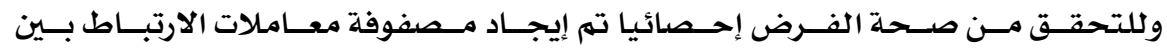

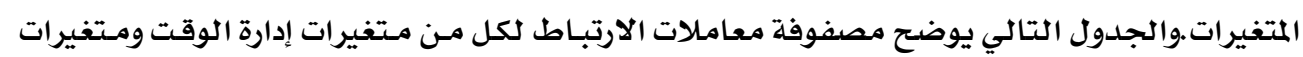
السياحة الداخلية. 
جدول رقم ( 0) مصفوفة معامل الارتباط بين كل من ممارسة أنشطة وقت الفراغِِ إِ السياحة

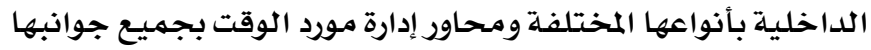

\begin{tabular}{|c|c|c|c|c|c|c|c|c|c|c|}
\hline |الداخلية & الرياضياحة & الترفياحة & سياحة & الثقافياحة & إدارة إدارت & تقيم & تنفيذ & تخطيط & تحلديد & بيان \\
\hline & & & & & & & & & - & تحديد الهدف \\
\hline & & & & & & & & - & $* *, r M r$ & تخطيط \\
\hline & & & & & & & - & $* *, 107$ &, $1 \varepsilon-$ & تنفيذ \\
\hline & & & & & & - & $* *, 17 \pi$ & $\% \&, r r \varepsilon$ & $* *, Y \backslash \Lambda$ & تقيه \\
\hline & & & & & - & $* *$, , 0 \& & $* *, 0 \leq \varepsilon$ & $* *, 77$. & $* *, 0 \wedge 7$ & إدارة الوقت \\
\hline & & & & - & $* *, o v$. & $* *, r \wedge r$ & $* *, \mathrm{rro}$ & $* *, r r$. & $* *, r \leqslant q$ & الثقياحة الثية \\
\hline & & & - & $*, 1 \cdot v$ & $* *, Y Y I$ & $* *, 1 \leqslant \Lambda$ & $*, 11 \pi$ & $* *, 1 \leqslant 1$ & $* *, \mid r \wedge$ & سياحـة الآثار \\
\hline & & - & $* *, 000$ & $*, 1 \cdot 7$ & $* *, r \vee \varepsilon$ & $* \$, 170$ & $* *, 107$ & $* *, 17 r$ & $* *, I V r$ & الترفيهية احية \\
\hline & - & $* *, I r r$ & *** & $* *$, , IV & , $\{r-$ & , $\wedge$ - & ,or - & , &,.$\leqslant \varepsilon-$ & الرياضياحية \\
\hline & $* *, 070$ & $\$ *, 070$ & $*, 00 \xi$ & $* *,+19$ & $* *, r q 1$ & $* *, Y 01$ & $* *, 191$ & $* *, r \wedge I$ & $* *, Y Y Y$ & |الداخلية كلياحة \\
\hline
\end{tabular}

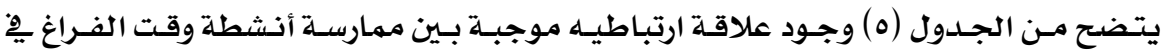
السياحة الداخلية ومحاور إدارة الوقت عند مستوى دلاله (

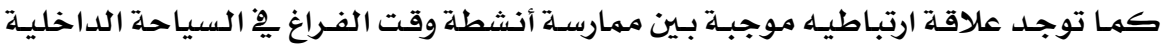

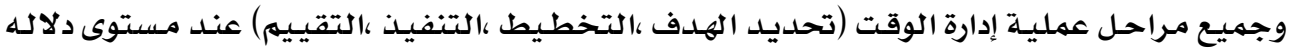
$(*, .1)$

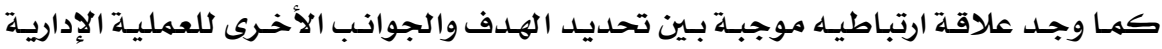

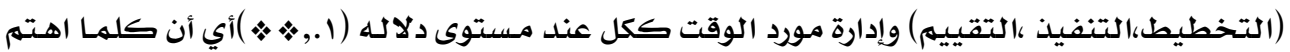

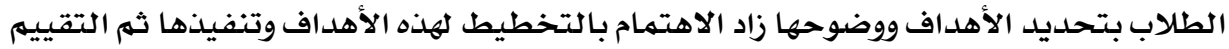
كما وجـد علاقـة ارتباطيـه بـين إدارة مـورد الوقت و ممارسـة أنشطة وقت الفـراغ يِّ السياحسة

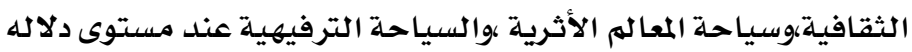

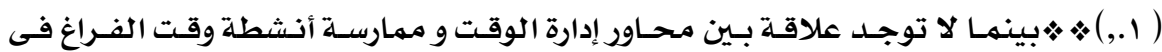

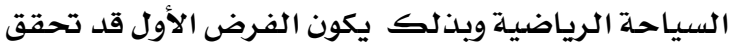


r- ب الفرض الثاني : وينص على انه:

\section{توجد فروق ذات دلاله إحصائية بين الشباب( ذكوروإناث ) مِّ إدارة مورد الوقت}

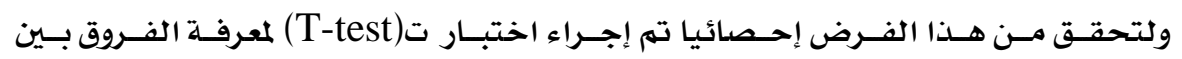

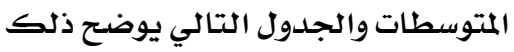

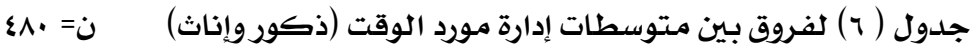

\begin{tabular}{|c|c|c|c|c|c|c|c|c|}
\hline \multirow[b]{2}{*}{ لصالح } & \multirow{2}{*}{ مستوى الدلادة } & \multirow{2}{*}{ قيمة } & \multirow{2}{*}{ |المتوسطروق بين } & \multicolumn{2}{|c|}{ إناث= r r r } & \multicolumn{2}{|c|}{ ذكورن=آن } & \multirow[b]{2}{*}{ بيـان } \\
\hline & & & & الانحراف المعياري & المتوسط الحسابي & الانحراف المعياري & المتوسط الحسابي & \\
\hline الإناث & $\$, .0$ & $r, \cdot V_{0}$ & $1, \varepsilon \leqslant V Y$ & $r, \varepsilon \leqslant 0$. & $Y Y, \varepsilon \wedge \wedge O$ & $r, 0717$ & Yl. & تحديد الهدف \\
\hline ل إناث & $* *, .1$ & $r, 71$ & 1, $\varepsilon \wedge \mu$ & $r .079$ & YII,VI. & $r, 719$ & $r \cdot, r Y r$ & التخطيط \\
\hline ل الإناث & $\$, .0$ & 1,917 & $1,71 \cdot \varepsilon$ & r,rr. 9 & YY,VYI. & 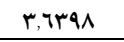 & $r \cdot, 77 \cdot 7$ & التنفيذ \\
\hline- & لا يوجد دلالة & , TVq & (r & $r, \varepsilon q \wedge$. & $r \cdot, 79 \leqslant V$ & r,rrug & $r \cdot, \varepsilon \wedge I V$ & التقييم \\
\hline ل ل ل لإناث & $* *,+1$ & $\mathrm{r}, 00 \mathrm{~V}$ & $1,990$. & $\Lambda, \cdots r r$ & $\Lambda \Lambda \cdot r \cdot 0$ & $\Lambda, \varepsilon O \wedge Y$ & $\Lambda 7,1.00$ & إجمالي إدارة الوقت \\
\hline
\end{tabular}

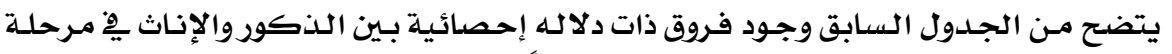

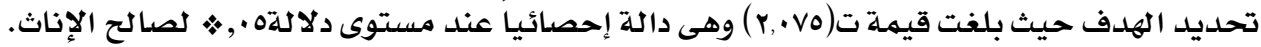
توجد فروق ذات دلالة إحصائية بين الذكوروالإناث ِِّ مرحلة التخطيط لصالح الإناث حيث

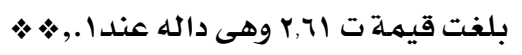

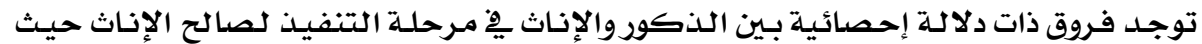

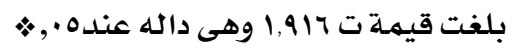

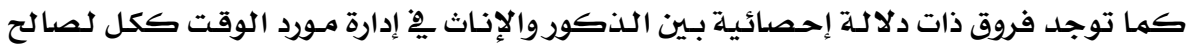

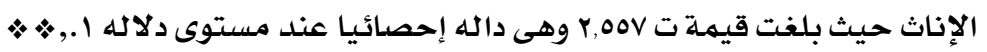

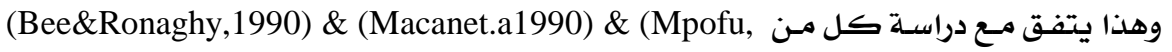
التي توصلت إلى أن الإناث يتفوقن على \&amico, cleghorn1995) \& (Trueman \& Hartleg1996) الذكور ِِّ مهارات إدارة الوقت

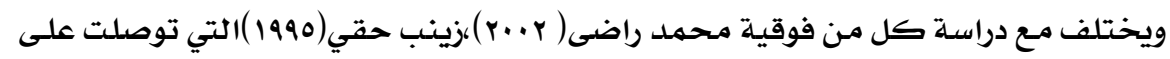

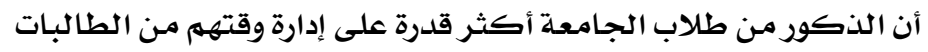

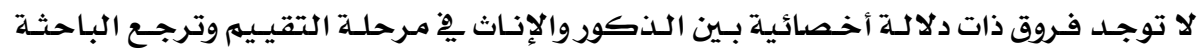

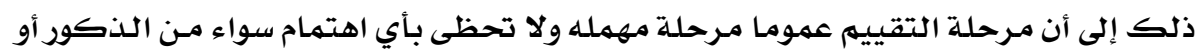
الإناث

وبذلك يكون الفرض قد تحقق جزئيا 


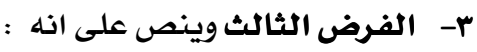

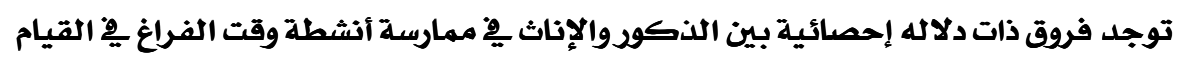

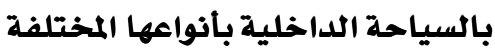

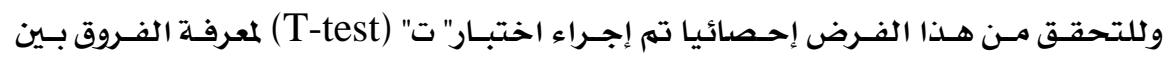

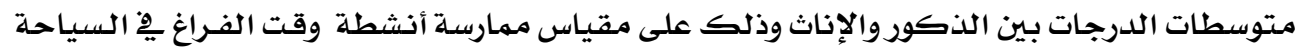

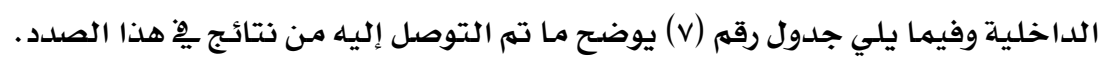

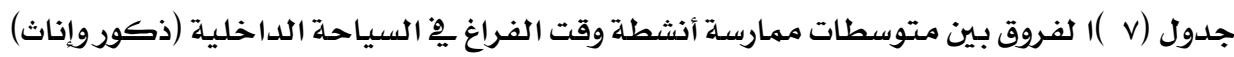

$\varepsilon \wedge \cdot=\dot{ن}$

\begin{tabular}{|c|c|c|c|c|c|c|c|c|}
\hline \multirow[t]{2}{*}{ لصالح } & \multirow{2}{*}{ مستوى الدلادة } & \multirow{2}{*}{ قيمة } & \multirow{2}{*}{ |المتروق بين } & \multicolumn{2}{|c|}{ إناث= r r } & \multicolumn{2}{|c|}{ ذكورن=YM } & \multirow[b]{2}{*}{ بيـان } \\
\hline & & & & الانحراف المعياري & المتوسط الحسابي & الانحراف & المتوسط الحسابي & \\
\hline الإإناث & $* * *, . .1$ & $r, \varepsilon q r$ & , VYq. & r,rvos & $9, Y \cdot 71$ & r.loro & $\wedge, \varepsilon \vee \vee \backslash$ & سياحلة ثقافية \\
\hline 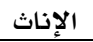 &,$\cdots \wedge$ & $r, 7 \leqslant q$ & ,00Yo & r,rVVr & $9, \leqslant 0 \leqslant Y$ & r,IYTY & $\Lambda, q \cdot r v$ & سياحة المعالم الأثرية \\
\hline الذكور &,$\cdots 7$ & $r, \cdots o$ & $1, T$ TYA. & $r, I r \leqslant 0$ & $9, \cdot \varepsilon 14$ & Y,rq. T & $1 \cdot, 77 \leqslant 1$ & سياحة ترفيهية \\
\hline الذكور &,$* * * .1$ & ( & V,rTIN & $r, r \cdot V r$ & r,OAVA & $r, r \cdot V r$ & $1 \cdot, 9 \leqslant 90$ & سياحة رياضية \\
\hline الذكور & $* *, . .1$ & $\mid r, 7 \cdot \Lambda$ & $0,7 \ldots 0$ & $\varepsilon, \wedge 701$ & rY,AVY & $\varepsilon, \wedge$ YOY & rA,EVYO & السياحة الداخلية ككل \\
\hline
\end{tabular}

يتضـح من الجدول السـابق وجـود فروق ذات دلالـه إحصائية بـين الذكوروالإناث ِِّ ممارسسة

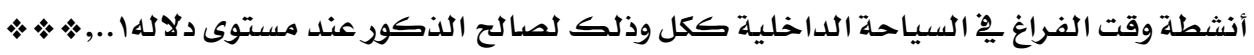

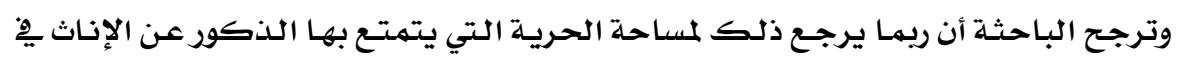

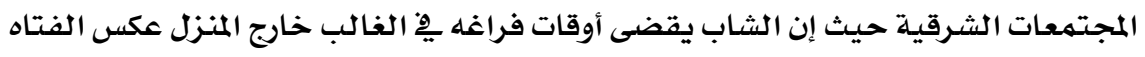

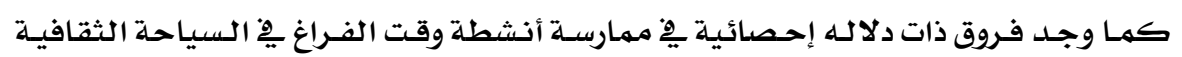

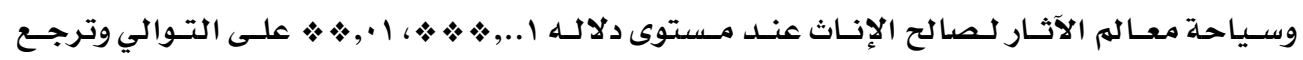

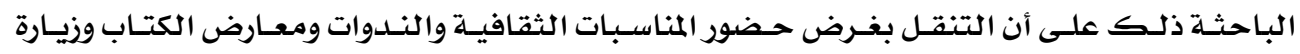

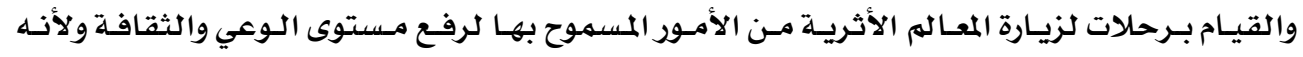
المتنفس الوحيد لدى الإناث

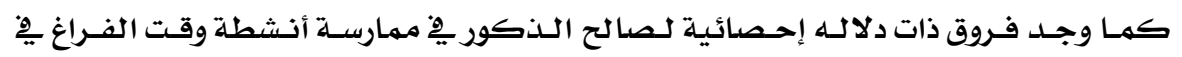

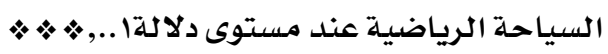

ووجدت فروق ذات دلاله إحصائية لصالح الذكور ِِّ ممارسة أنشطة وقت الفراغ يِّ السياحة

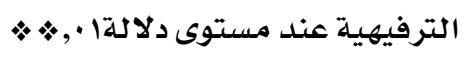

وبذلك يكون فرض الدراسة الثالث قد تحقق 


$$
\text { ع- الفرض الرابع وينص على }
$$

أنه يوجد تأثير دال إحصائيا لإدارة الطلاب لمورد الوقت بجميع جوانبها تبعاء لمستوى تعليم

وللتحقـق مـن صسحة هـذا الفـرض تم اسـتخدام تحليـل التبـاين يف اتجـاه واحسـ لإدارة مـورد

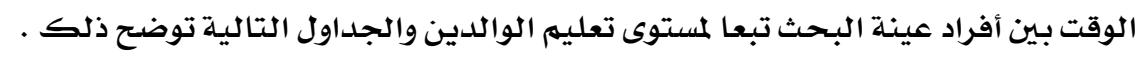

جدول رقم (^ ) تحليل التباين يِّ اتجاه واحد لإدارة مورد الوقت بجميع جوانبها تبعا تبعا لمستوى تعليم الأم

\begin{tabular}{|c|c|c|c|c|c|c|}
\hline مستوى & ق فيمة & مترسط المربعات & درجات & مجرموع المربعات & مصدر التباين & المتغير والتابع \\
\hline دالة. & 10,01 & $\begin{array}{l}1 V 0, \cdot \varepsilon V \\
11, r \mu V\end{array}$ & $\begin{array}{c}1 \\
\varepsilon \vee \wedge \\
\varepsilon \vee q\end{array}$ & 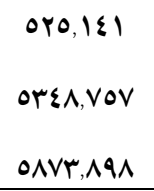 & بين المجموعات التبل المجموعاتين الكلى & تحديد الهدف \\
\hline دالة & rq, r & $\begin{array}{l}\mathrm{rq} \cdot \mathrm{ov} \text {. } \\
1 \cdot, \cdot 11\end{array}$ & $\begin{array}{l}1 \\
\varepsilon \vee \wedge \\
\varepsilon \vee 9 \\
\end{array}$ & $\begin{array}{l}1 \cdot \wedge 1, V \| 1 \\
\varepsilon \vee 70, \varepsilon \Psi V \\
0 \wedge \varepsilon V, 1 \leqslant \wedge\end{array}$ & باخين المجموعات التباين المجموعات & التخطيط \\
\hline دالة & $r \cdot r \varepsilon$ & $\begin{array}{l}r m, 0 . r \\
11,0 V \varepsilon\end{array}$ & $\begin{array}{l}1 \\
\sum \vee \wedge \\
\sum \vee 9 \\
\end{array}$ & $\begin{array}{l}V \cdot 9,0 \cdot 0 \\
00 \cdot 9, r \cdot V \\
7 Y M, V 9 r\end{array}$ & باخين المجموعات التباين المجموعات & التتفيذ \\
\hline دالة & ro,ru & $\begin{array}{l}r \varepsilon \cdot, r V o \\
q, 7 r q\end{array}$ & $\begin{array}{c}1 \\
\varepsilon \vee \wedge \\
\varepsilon \vee \vee\end{array}$ & $\begin{array}{l}\text { I. YI,IYE } \\
\text { \&OMA,YVE } \\
07.9, r 9 \Lambda\end{array}$ & داخل المبن المجموعات & التقييم \\
\hline دالة & 91, Yo. & $\begin{array}{l}\varepsilon r \cdot 0, q r q . \\
\varepsilon \vee, 1 \wedge q\end{array}$ & $\begin{array}{c}1 \\
\varepsilon \vee \wedge \\
\varepsilon \vee q\end{array}$ & $\begin{array}{l}\text { IrqIV,AIV } \\
\text { rrsqI, vVo } \\
\text { rorva,oqr }\end{array}$ & داخل المبن المجموعات & مورد الكمالي إدارة \\
\hline
\end{tabular}

يتضح من الجدول السـابق وجود تأثير دال إحصائيا لإدارة مورد الوقت بجميع جوانبها تبعـا

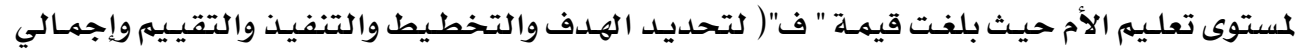

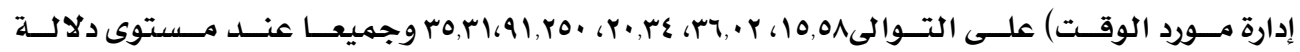




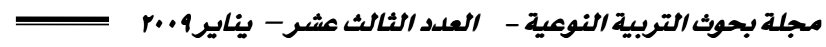

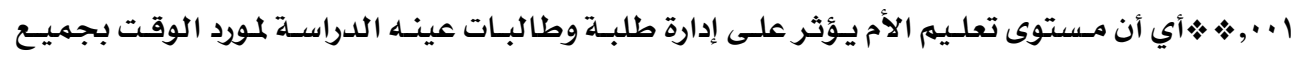
جوانبها جدول رقم ( ه )تحليل التباين يِّ اتجاه واحد لإدارة مورد الوقت بجميع جوانبها

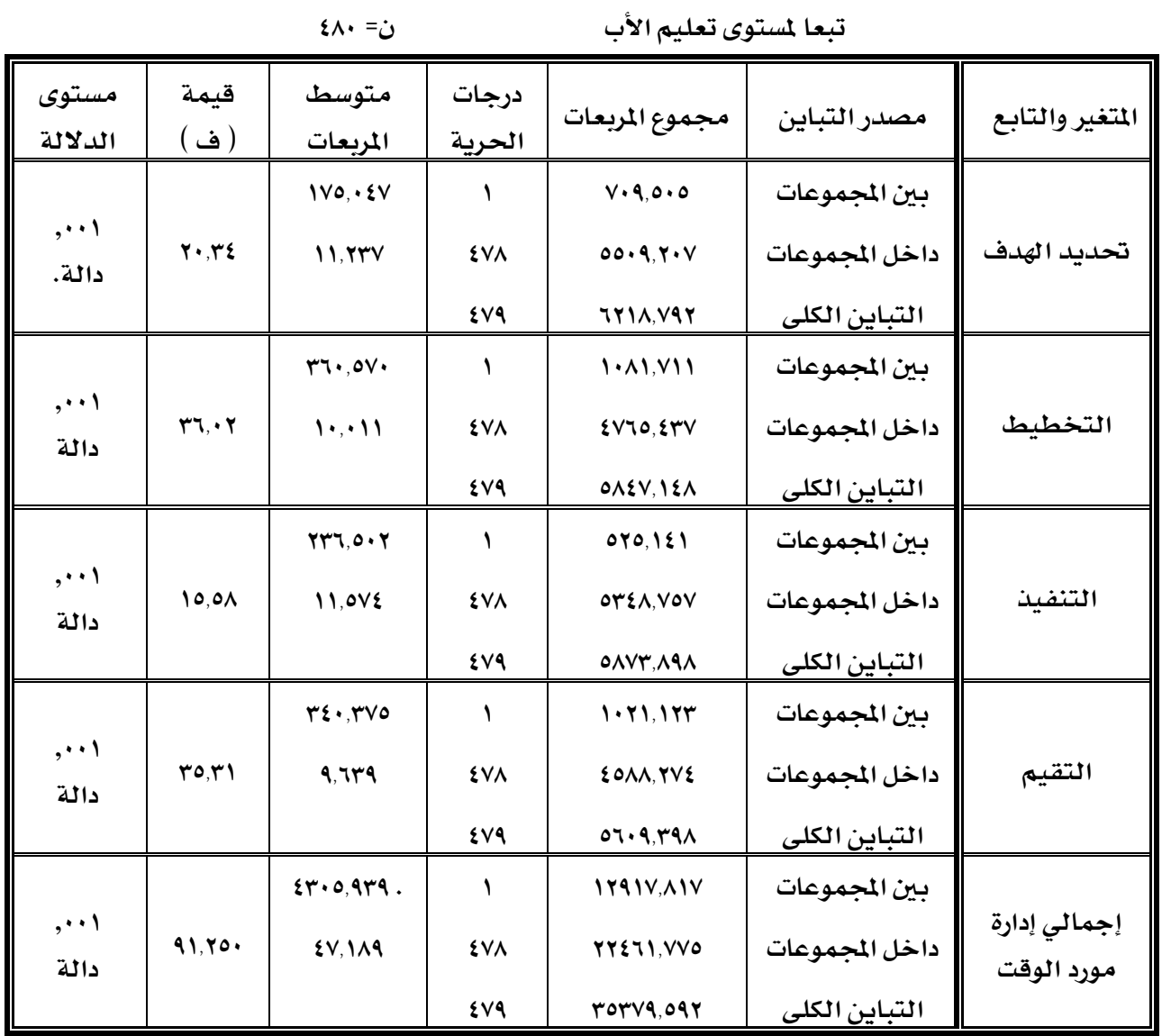

يتضـح من الجدول السابق وجود تفاعل دال إحصائيا بـين إدارة مـورد الوقت بجميع جوانبها

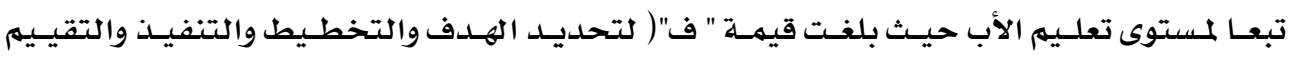

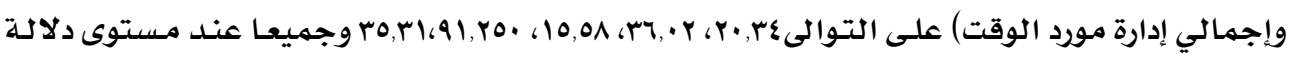

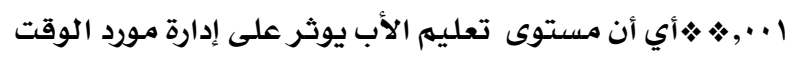

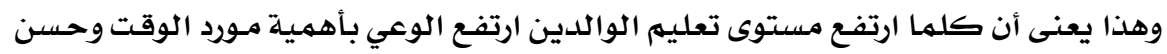

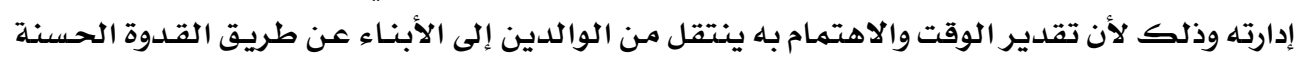

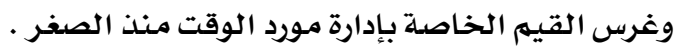




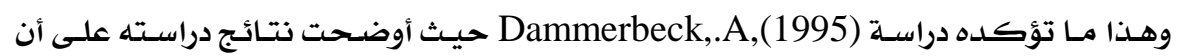

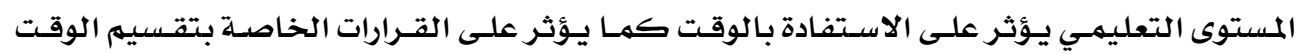

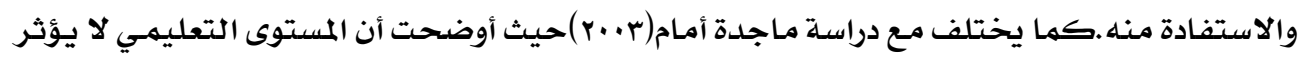

$$
\text { على إدارة مورد الوقت . مادة منهاه }
$$

وبذلك يكون فرض الدراسـة قد تحقق.

0- فرض الدراسة الخامس :

وينص على أنه توجد فروق دالة إحصائيا يِّ إدارة مورد الوقت باختلاف مكان السكن( ريف، حضر ). وللتحقق مـن صـحة هـذا الفـرض تم إجـراء تحليـل التبـاين أحسادى الاتجـاه والجـدول التـالي يوضتح ذلك

جدول ( ـ ا ) تحليل التباين يِّ اتجاه واحد لإدارة مورد الوقت بجميع جوانبها

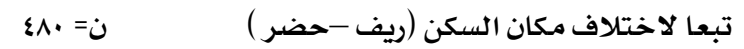

\begin{tabular}{|c|c|c|c|c|c|c|}
\hline مستوى الدلالة & ق فيمة & متوسط المربعات & درجات & مجرموع & مصدر التباين & المتغير والتابع \\
\hline r. &, $1 \leqslant 7$ & $\begin{array}{l}\text { I,VA9 } \\
\text { Ir,Y^o }\end{array}$ & $\begin{array}{c}1 \\
\varepsilon \vee \wedge \\
\varepsilon \vee q\end{array}$ & 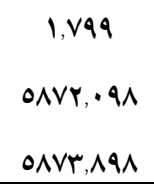 & داخل المجموعات المجموعات & تحديد الهدف \\
\hline גוo, غير & ( & $\begin{array}{l}\varepsilon, \Lambda T V \\
\text { IY,YYY }\end{array}$ & $\begin{array}{l}1 \\
\varepsilon \vee \wedge \\
\varepsilon \vee q \\
\end{array}$ & 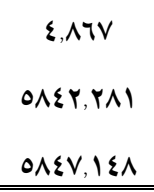 & 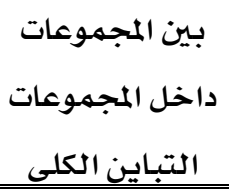 & التخطيط \\
\hline • الآ, غير & , ז . & $\begin{array}{l}r, r \wedge \mid \\
\mid r, \cdot \cdots r\end{array}$ & $\begin{array}{c}1 \\
\varepsilon \vee \wedge \\
\varepsilon \vee 9 \\
\end{array}$ & 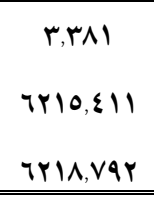 & بالبن المجموعات المجموعات & التنفيذ \\
\hline دال, غير &,$\cdots 1$ & $\begin{array}{l}1,7 \leqslant 0 . r \\
11, \mathrm{Vro}\end{array}$ & $\begin{array}{l}1 \\
\varepsilon \vee \wedge \\
\varepsilon \vee 9 \\
\end{array}$ & $\begin{array}{l}1,7 \varepsilon 0.4 \\
07 \cdot 9,4997 \\
07 \cdot 9,491 \\
\end{array}$ & باخل المبن المجموعات & التقييم \\
\hline 119, غير & , or & $\begin{array}{l}r, \wedge \wedge 0 \\
\vee \varepsilon, \cdots \wedge\end{array}$ & $\begin{array}{l}1 \\
\varepsilon \vee \wedge \\
\varepsilon \vee q\end{array}$ & $\begin{array}{l}\text { r,A10 } \\
\text { rorvo,v.V } \\
\text { rorvq, Q9Y }\end{array}$ & داخل المجموعات المجموعات & مورد الكمقت إدارة \\
\hline
\end{tabular}




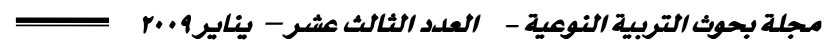

يتـــ مــن الجـــول الـسـابق عـدم وجـود تفاعـل دال إحــصائيـا لإدارة مـورد الوقـت بجـوانبهـا

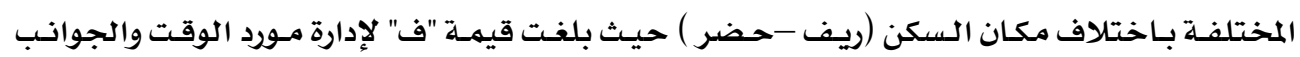

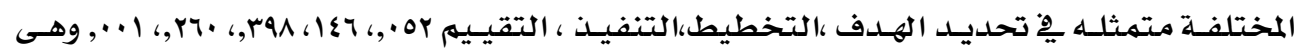

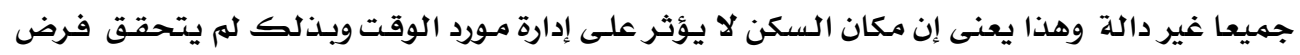
الدراسـة جهيعا

فرض الدراسة السادس:

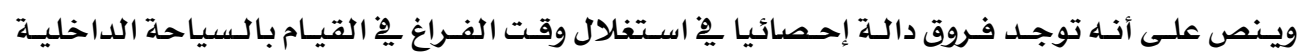
بأنواعها المختلفة باختلاف مكان السكن (ريف، حضر) . وللتحقـق مـن صسحة هـذا الفـرض تم إجـراء تحليـل التبـاين أحـادى الاتجـاه والجـــول التـالي يوضتح ذلك

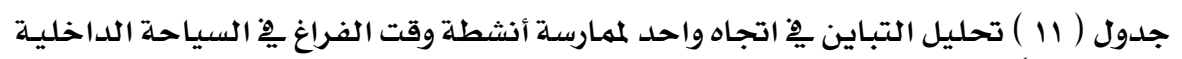

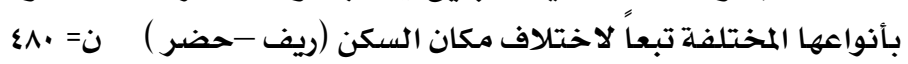

\begin{tabular}{|c|c|c|c|c|c|c|}
\hline مستوى الدلالة & قيمـة & مترسط المربعات & درجـات & مجرجموع المربعات & مصلدر التباين & المتغير والتابع \\
\hline ساן , غير داله & $Y, 019$ & $\begin{array}{l}1 r, \varepsilon \leqslant 1 \\
0, r r q\end{array}$ & $\begin{array}{c}1 \\
\varepsilon \vee \wedge \\
\varepsilon \vee q\end{array}$ & $\begin{array}{l}\text { Ir, } \varepsilon \leqslant 1 \\
\text { roor, I\&r } \\
\text { roro,09r }\end{array}$ & بـين المجموعات التبل المجموعات & السياحة الثقافية \\
\hline$*, \cdots 1$ & $\wedge, \vee ৭ 0$ & $\begin{array}{l}\{Y, 91\} \\
\varepsilon, M .\end{array}$ & $\begin{array}{c}1 \\
\varepsilon \vee \wedge \\
\varepsilon \vee 9\end{array}$ & $\begin{array}{l}\text { \&Y,Q1\} } \\
\text { rmrY,\&।I } \\
\text { rrVO,rYo }\end{array}$ & داخل بـن المجموعات المجمهوعات & سياحة معالم \\
\hline$* * *, \ldots 1$ & $r \cdot, 0 \wedge r$ & $\begin{array}{l}\text { IrV, } Y \varepsilon V \\
\varepsilon, 0.1\end{array}$ & $\begin{array}{c}1 \\
\varepsilon \vee v 1 \\
\varepsilon \vee 9 \\
\end{array}$ & 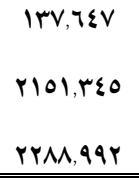 & بـين المجموعات التبل المجموعات & السياحة \\
\hline سץو, غير داله &,$\cdots 9$ & $\begin{array}{l}\text {,IN1 } \\
\text { 19,YYE }\end{array}$ & $\begin{array}{c}1 \\
\varepsilon \vee \wedge \\
\varepsilon \vee \vee \\
\end{array}$ & $\begin{array}{l}\text {,|11 } \\
\text { 9rru, AIV } \\
9 \text { 9ru,991 }\end{array}$ & داخل المبن المجموعات & السياحة الرياضية \\
\hline داله & $17,0 \leqslant V$ & $\begin{array}{l}0 ., T \wedge r \\
r, r \circ q\end{array}$ & $\begin{array}{c}1 \\
\varepsilon \vee \wedge \\
\varepsilon \vee 9\end{array}$ & $\begin{array}{l}0 \cdots, 7 \wedge Y \\
1 \leqslant \varepsilon 7 r, \Lambda 10 \\
1 \leqslant 97 \varepsilon, \leqslant 9 \Lambda\end{array}$ & داخل المين المجموعات المبموعات & إجمالي استغلال \\
\hline
\end{tabular}


يتضح من الجدول السـابق وجود تفاعل دال إحصائيا ممارسـة أنثطة وقت الفراغ يِّان السياحة

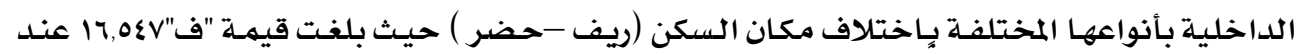

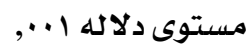

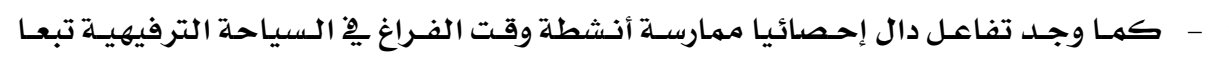

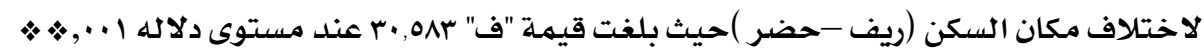

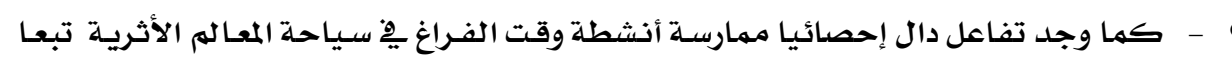

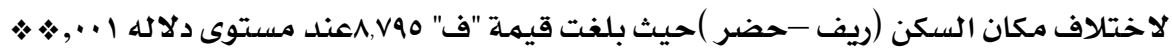

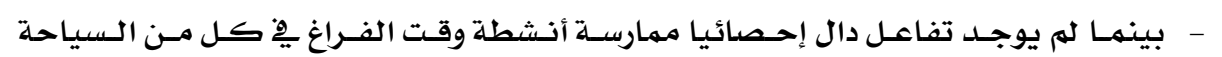

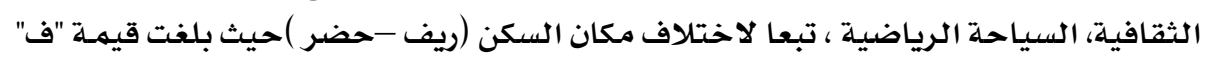

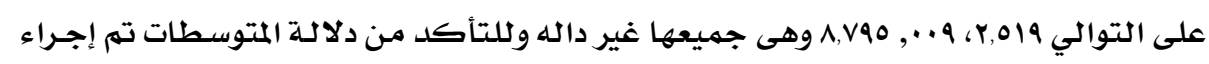

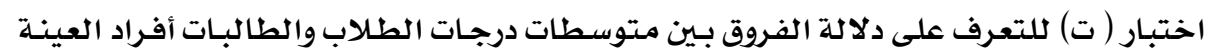

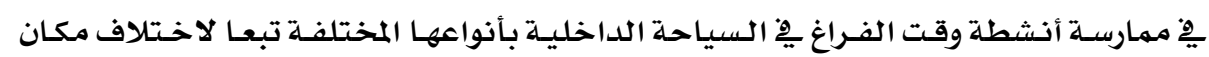

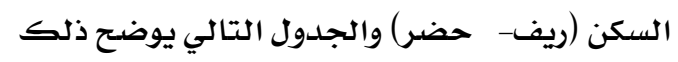

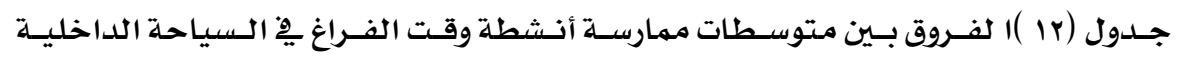

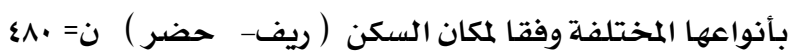

\begin{tabular}{|c|c|c|c|c|c|c|c|c|}
\hline \multirow[b]{2}{*}{ لصالح } & \multirow{2}{*}{ |لدستوى | الدلة } & \multirow{2}{*}{ قيمة } & \multirow{2}{*}{ المتروق بين } & \multicolumn{2}{|c|}{ حضر =r.r } & \multicolumn{2}{|c|}{ ريف ن=|VN } & \multirow[b]{2}{*}{ بيان } \\
\hline & & & & الانحراف & الحتوسط الحسبي & الانحراف المعياري & المتوسط الحسابي & \\
\hline |الحضر & , lir & $1,01 \mathrm{~V}-$ &,$r \leqslant 70$ & r,YYTE & 9.994 & r,YArV & A,VOYA & سياحة ثقافية \\
\hline |الحضر &,$\cdots r$ & r.977 - & , 719. & r,rrll & 9,7941 & $r, I V \cdot V$ & $9, \cdot v r$. & سياحة المعالم \\
\hline الحضر &,$\cdots 1$ & 0,or. - & $1,1 \cdot 17$ & $r, 1.09$ & $1 ., 50 \mathrm{~V}$. & $r, I \leqslant V V$ & $9, r \xi \wedge \mu$ & سياحة ترفيهية \\
\hline |الحضر & מצr &, $.9 V-$ & $\varepsilon, \cdot Y r$. & $\varepsilon, \varepsilon$ Y०४ & $7,90 \cdot r$ & $\varepsilon, r \xi \xi \Gamma$ & $7,91 \cdot 1$ & سياحة رياضية \\
\hline |الحضر &,$\cdots 1$ & $\varepsilon, 71-$ & $r, 11 \leqslant \varepsilon$ & $0, T I M Y$ & $m \Psi, 191 \mathrm{~V}$ & $0, r \cdot \xi r$ & $r \xi, \wedge \xi r$ & الداخلية ككل السياحة \\
\hline
\end{tabular}

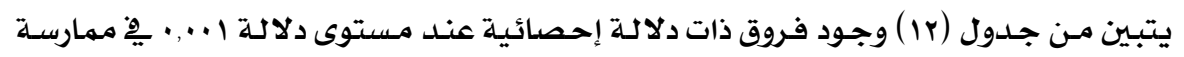

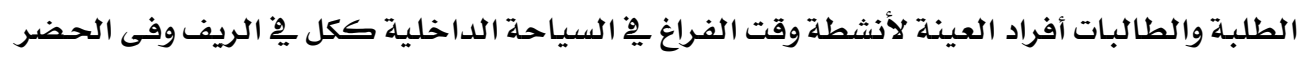

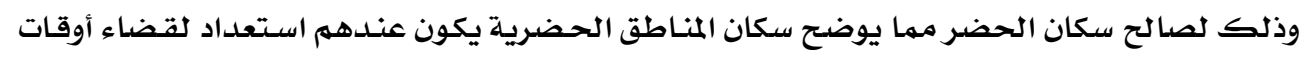

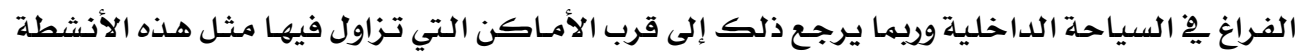

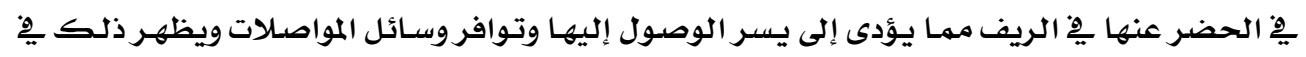

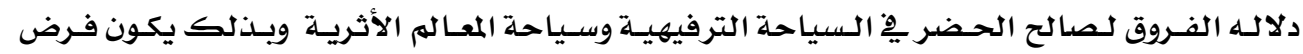

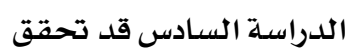




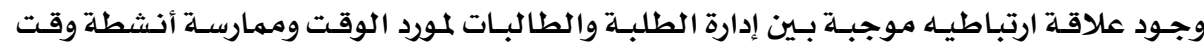

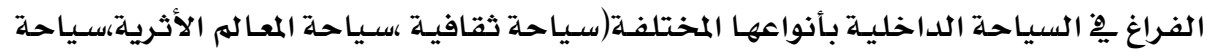

ترفيهية، سياحة رياضية)

توجد علاقة ارتباطيه موجبة بين ممارسـة الطلبـة والطالبـات لأنشطة وقت الفـراغِ ِِّ السياحة

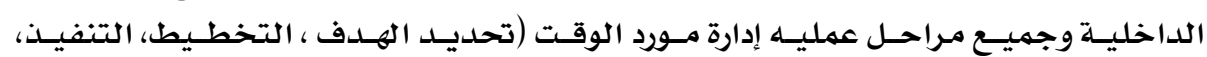

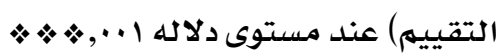

وجود تفاعل دال إحصائيا لممارسة أنشطة وقت الفـراغ ِِّ السياحة الداخليـة بأنواعها المختلفـة

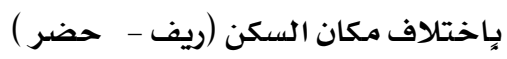

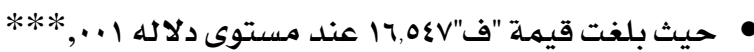

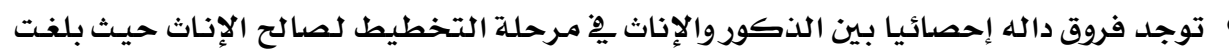

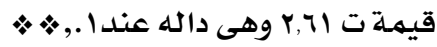

وجود فروق ذات دلاله إحصائية بين الذكور والإناث ِِّ ممارسسة أنشطة وقت الفـراغ ِِّ السياحة

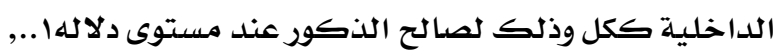

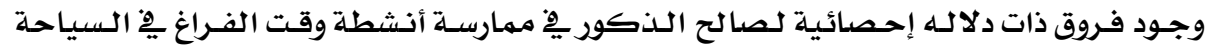
الرياضية

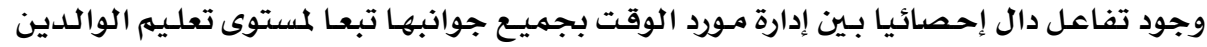

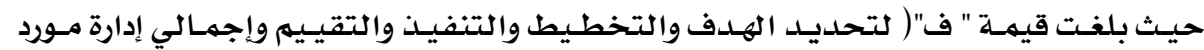

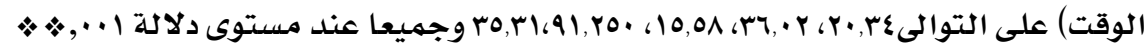
• علدم وجـود تفاعل دال إحصـائيا لإدارة مـورد الوقت بجوانبها المختلفـة بـاختلاف مكـان السكن

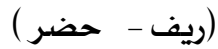

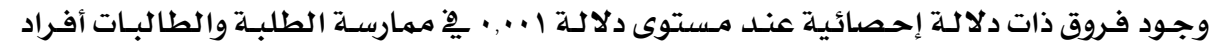

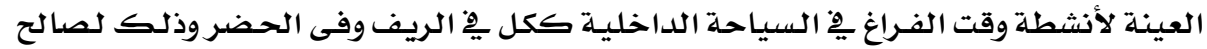
سكان الحضر التوصيات وفقاً لنتائج البحث توصى الباحثة بها يلي :

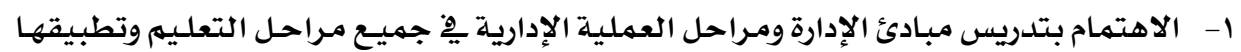

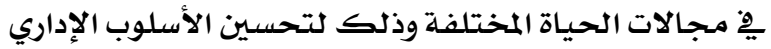

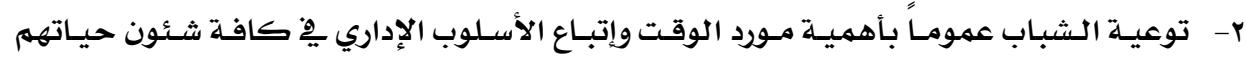

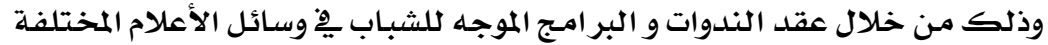


r- تشجيع قيام الشباب بالسياحة الداخلية وذلك بلدعم الرحلات مـن الجهات المسئولة للسماح

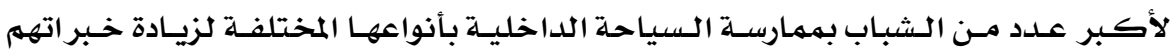
وتنميـه شخصياتهم ع- محاولة التعرف على حجم مشكلة الفراغ بين الشباب وأسبابها، والتعـرف على الأمـاكن التي

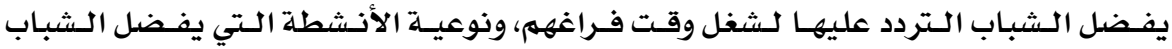

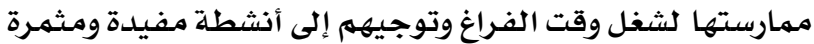

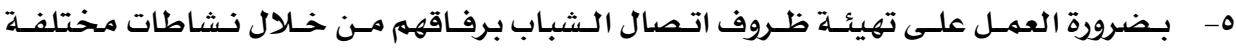

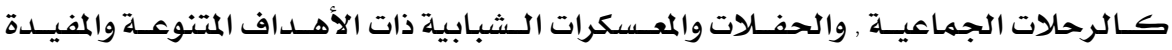

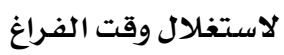
تبصير الشباب من الجنسين بأهمية الموارد وذلك بإدراج مقررات تحتوفى على الموارد البشرية

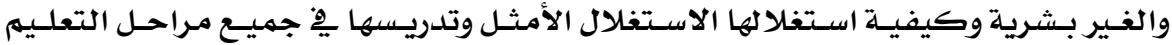

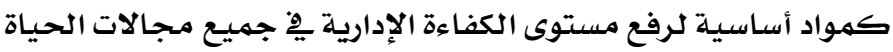

\section{أولا المرابج العربية}

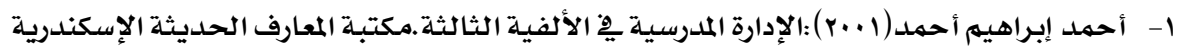

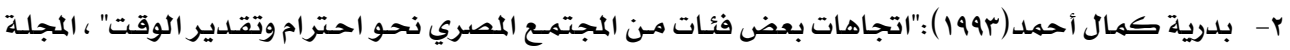

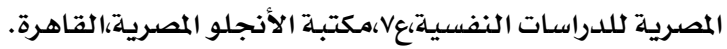

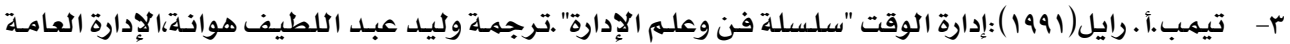

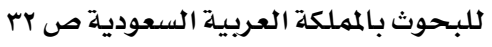

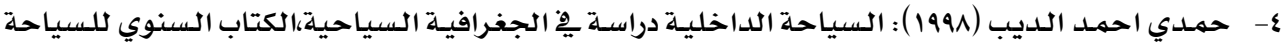

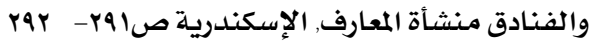

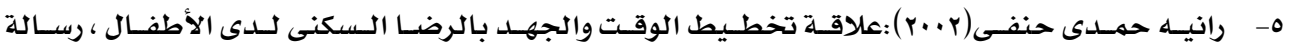

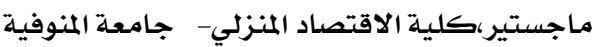

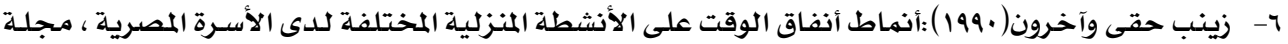

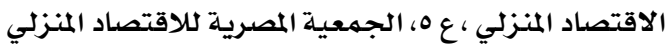

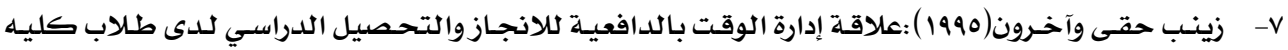

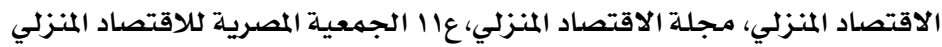

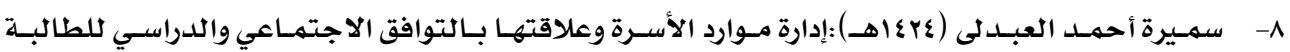

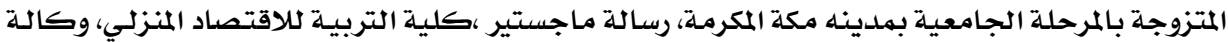
كليات البنات 9- سهير نور وآخرون ( 1994) : اقتصاديات الاستهلاك الأسرى ، جامعة الإسكندرية

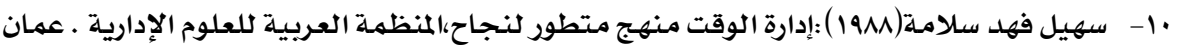




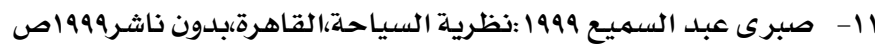

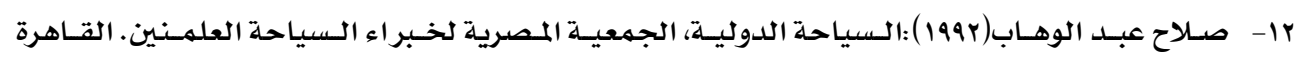
ص.re

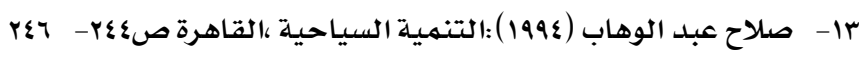

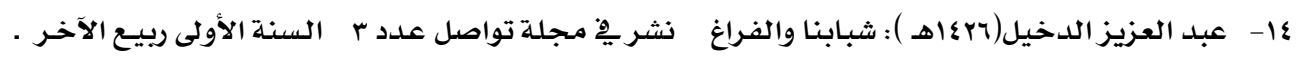

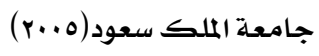

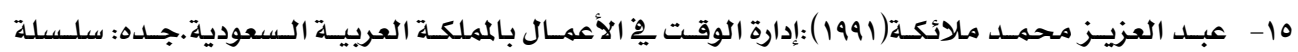

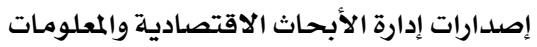

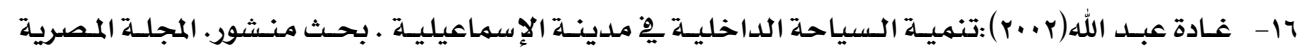

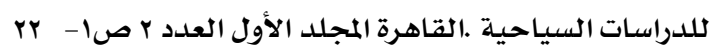
Vا - فاروق عثمان (1990) :سيكولوجية إدارة الوقت :تنمية مهارات التفكير الاستراتيجي, دار المعارف ـ القاهرة

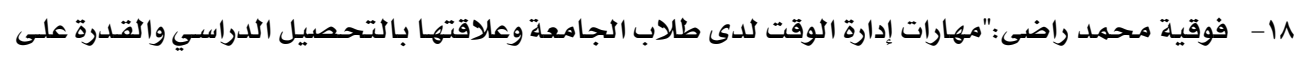

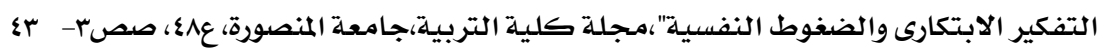

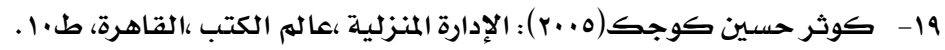

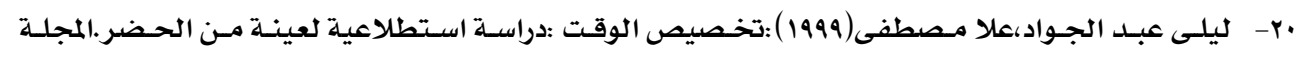

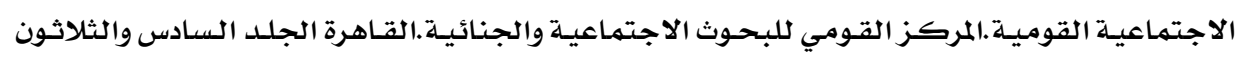

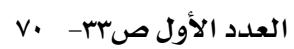

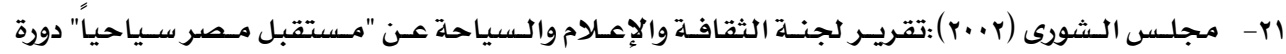
V. الانعقاد الحادي والعشرون ص

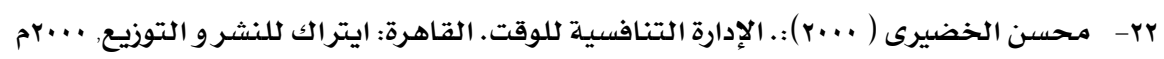
سץ- محمد عبد الغنى (1990): مهارات إدارة الوقت :كيف تدير وقتك بكفاءة، مركز تطوير الأداء والتنميـة. القاهرة

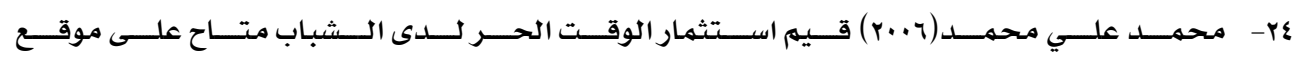
http://www.balagh.com

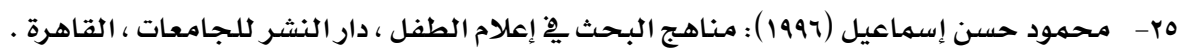

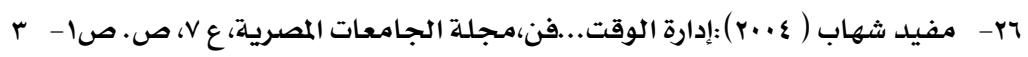

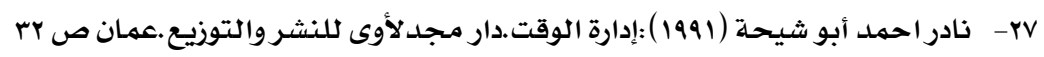

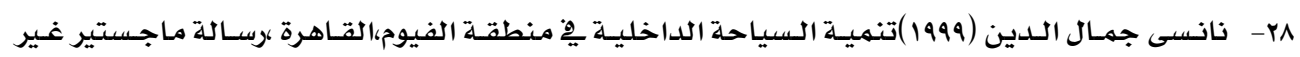
منشورة،جامعة حلوان

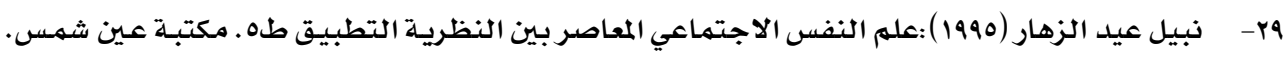
القاهرة

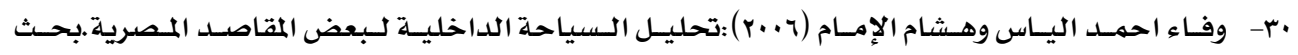

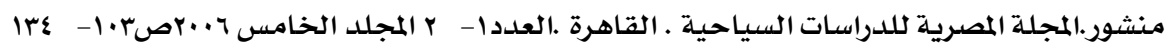

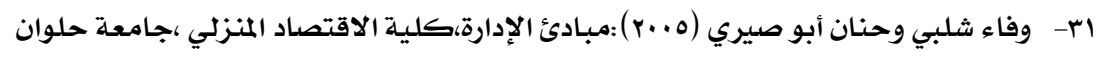




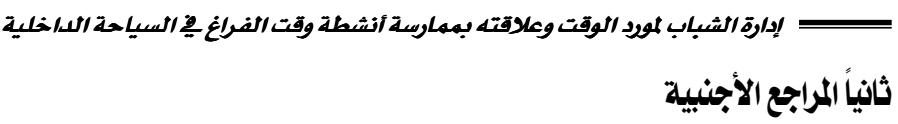

32. Bee,R.,\&Ronaghy,H.(1990).A time budget analyis of collegiate major. college Student Journal,24,72-77

33. Britton,B,,A.\&Tesser(1991):Effect of time-management practices on college grades. Journal of Education psychology, 83, 3, 405-410. Britton\&Tesser, 1991

34. BTR, 1997: International Vistor survey 18- 341997 Comberra: Burea of Tourism Research

35. Dammer,beckanne,M.(1995):The Political Economy Of The Family A study Of Household Time Use Decision University Of Missouri-Columbia

36. Helmer,p.(2001):Time Management for Engineers and Constructors

37. Jeffris, D., (2001): Governments and Tourism Butter worth Heinemann, UK, pp. 143-144

38. Macan,T.,\&Others.(1990).College students time management : Correlations with academic performance and stress. Journal of Educational psychology,82,4,760-768

39. Mpofu, E.,Damico, M., \& Cleghorn ,A.(1996).Time management practices in an African culture:Correlates with college academic grades.Canadian Journal of Behavioral Science,28,2,102-112

40. Trueman,M., \& Hartley, J.(1996). Acomparison between the time management skills and academic performance of mature and traditional-entry university students.Higher Education,32,2,199-215

41. Urry,J.,Leisure and Social Identity, Time and Society, vol.3, no.2,1994,pp131149

42. Weaner D. and Oppermann, M., 2000: Tourism Management. -JohnWiley \&son, Ltd.Australia,pp3-4 